This article was downloaded by:[Swets Content Distribution]

On: 26 July 2007

Access Details: [subscription number 768307933]

Publisher: Psychology Press

Informa Ltd Registered in England and Wales Registered Number: 1072954

Registered office: Mortimer House, 37-41 Mortimer Street, London W1T 3JH, UK

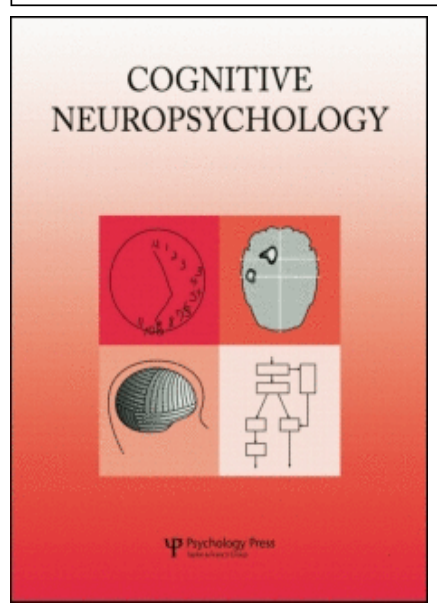

\title{
Cognitive Neuropsychology
}

Publication details, including instructions for authors and subscription information: http://www.informaworld.com/smpp/title content=t713659042

A semantic contribution to nonword recall? Evidence for intact phonological processes in semantic dementia

Elizabeth Jefferies ${ }^{\text {a; }}$ Roy W. Jones ${ }^{\text {b; }}$ David Bateman ${ }^{\text {c; }}$ Matthew A. Lambon Ralph

a University of Bristol, UK

b St Martin's Hospital, Bath, UK

${ }^{\mathrm{c}}$ Royal United Hospital, Bath, UK

d University of Manchester, UK

Online Publication Date: 01 March 2005

To cite this Article: Jefferies, Elizabeth, Jones, Roy W., Bateman, David and Ralph, Matthew A. Lambon (2005) 'A semantic contribution to nonword recall? Evidence for intact phonological processes in semantic dementia', Cognitive Neuropsychology,

$22: 2,183-212$

To link to this article: DOI: $10.1080 / 02643290442000068$

URL: http://dx.doi.org/10.1080/02643290442000068

\section{PLEASE SCROLL DOWN FOR ARTICLE}

Full terms and conditions of use: http://www.informaworld.com/terms-and-conditions-of-access.pdf

This article maybe used for research, teaching and private study purposes. Any substantial or systematic reproduction, re-distribution, re-selling, loan or sub-licensing, systematic supply or distribution in any form to anyone is expressly forbidden.

The publisher does not give any warranty express or implied or make any representation that the contents will be complete or accurate or up to date. The accuracy of any instructions, formulae and drug doses should be independently verified with primary sources. The publisher shall not be liable for any loss, actions, claims, proceedings, demand or costs or damages whatsoever or howsoever caused arising directly or indirectly in connection with or arising out of the use of this material.

(c) Taylor and Francis 2007 


\title{
A SEMANTIC CONTRIBUTION TO NONWORD RECALL? EVIDENCE FOR INTACT PHONOLOGICAL PROCESSES IN SEMANTIC DEMENTIA
}

\author{
Elizabeth Jefferies \\ University of Bristol, $U K$ \\ Roy W. Jones \\ St Martin's Hospital, Bath, UK \\ David Bateman \\ Royal United Hospital, Bath, UK \\ Matthew A. Lambon Ralph \\ University of Manchester, UK
}

\begin{abstract}
Patients with semantic dementia make numerous phonological errors in their immediate serial recall of words that they understand poorly. Previous studies have argued that these errors result from a reduction in the normal contribution made by semantics to the coherence of items in the phonological system. It is possible, however, that the errors might reflect additional subtle phonological deficits. Six patients with semantic dementia were tested on a variety of phonological processing and short-term memory tasks, in order to explore these possibilities. For the most part, the patients showed normal performance in phonological awareness and discrimination tasks and normal effects of phonological similarity and word length in immediate serial recall. The more severely impaired patients, however, showed some weakness on tests of nonword repetition and recall. Every patient showed better recall of words that were still relatively well understood, compared with words that were more semantically degraded. This difference extended to nonwords that were phonologically similar to the known and degraded words, suggesting that the patients' semantic deficits could account for their impairments in nonword recall. The recall advantage for semantically known over degraded items also extended to a nonverbal delayed picture copying task, suggesting that the patients' immediate serial recall impairments were underpinned by a central semantic deficit, and not by a separable lexical deficit.
\end{abstract}

\section{INTRODUCTION}

This paper examines the role of semantics in phonological binding and short-term memory (STM) by considering the impact of semantic degradation on the immediate serial recall (ISR) of words and nonwords. Specifically, we will present data from patients with semantic dementia (SD), who have a specific and progressive impairment of semantic memory. $\mathrm{SD}$ is the temporal

Correspondence should be to addressed Elizabeth Jefferies, Dept of Psychology, University of Manchester, Oxford Road, Manchester, M13 9PL, UK (Email: beth.jefferies@man.ac.uk).

The first author, who is now at the University of Manchester, was supported by an ESRC studentship. 
variant of frontal-temporal dementia, and is associated with progressive focal atrophy of the infero-temporal neocortex that is typically more pronounced in the left hemisphere (Snowden, Goulding, \& Neary, 1989). Patients with SD display a highly uniform pattern of impairments; they are anomic and have impaired comprehension on both verbal and nonverbal tasks. In contrast, their perceptual and spatial skills, new episodic learning, nonverbal reasoning, syntax, and phonology remain largely intact, at least until the later stages of the disease (Hodges, Patterson, Oxbury, \& Funnell, 1992; Snowden, Neary, \& Mann, 1996).

SD patients are typically considered to have intact phonology because they rarely, if ever, make phonological errors in spontaneous speech or in naming to confrontation. Likewise, their single word repetition is excellent. In contrast, the ISR performance of apparently all SD patients is characterised by phonological breakdown, in which phonemes migrate to new positions in the list (McCarthy \& Warrington, 1987; Patterson, Graham, \& Hodges, 1994). For example, Patterson et al. reported that the onsets in the words "mint, rug" were exchanged in ISR to produce the response "rint, mug." Normal participants show a similar pattern of phonological migration errors in their serial recall of nonwords that, by definition, lack semantic representations (Treiman \& Danis, 1988). Furthermore, several studies of individual SD patients have found that more severe phonological disintegration occurs for words that have become poorly comprehended compared with words that are still understood relatively well (Jefferies, Jones, Bateman, \& Lambon Ralph, in press; Knott, Patterson, \& Hodges, 1997, 2000; Patterson et al., 1994). Similar findings have been reported in semantically impaired patients following cardiovascular accident (Forde \& Humphreys, 2002) and herpes simplex encephalitis (Caza, Belleville, \& Gilbert, 2002).

This striking association between semantic impairment and disintegration in phonological STM led Patterson et al. (1994) to propose that semantic memory makes a major contribution to the coherence of phonological representations.
According to this "semantic binding hypothesis," there are two sources of constraint that encourage the right configuration of phonological elements to be produced in both speech production and verbal STM tasks. First, because the elements of a word are always activated together when that word is produced, they become associated in the phonological system. Consequently, the phonological system develops pattern completion properties for familiar words. A second source of coherence is provided by the semantic system. Every time a word is spoken or comprehended, semantic activation co-occurs with phonological activation for that word. As a result, semantic activation can helpfully constrain the pattern of activation in the phonological system. This hypothesis, which posits distinct semantic and phonological representations but no separate lexical level, has its roots in the parallel distributed processing (PDP) models of, for example, Seidenberg and McClelland (1989) and Plaut and Kello (1999).

The frequent phoneme migration errors made by SD patients' in ISR tasks might also be consistent with the predictions of related approaches that incorporate localist representations and intermediate lexical-level nodes. N. Martin and Saffran (1997) sought to account for the verbal STM performance of aphasic patients within Dell and O'Seaghda's (1992) interactive activation model of word production, which consists of three layers of localist phonological, lexical, and semantic nodes. This model proposes that in ISR tasks, phonological activation spreads up to the lexical and semantic levels and then down again; consequently, semantic representations contribute to verbal STM by helping to sustain phonological activation.

The semantic binding hypothesis and its allies make two closely related predictions; first, that semantics supports the appropriate pattern of activation in the phonological system, and second, that the semantic system makes a crucial contribution to verbal STM. In fact, these proposals are equivalent in the context of these theories, as verbal STM and phonological processing are seen as being underpinned by the same representations. $\mathrm{SD}$ patients show phonological disintegration in 
ISR and delayed repetition but not in immediate single word repetition, consistent with the view that semantics makes a more crucial contribution to phonological coherence at longer time delays and with greater phonological loads. Phonemes from different words may recombine to produce a phonological error in these circumstances-either because the elements of several items are maintained simultaneously in the case of list recall, or because phonological decay allows the intrusion of phonemes from previous trials in the case of delayed single word repetition (see Knott et al., 1997). Given this, one might wonder why SD patients do not also make phonological errors in spontaneous speech or in picture naming. One solution would be to separate the representations involved in word production and ISR, as suggested by some researchers (e.g., Baddeley, Gathercole, \& Papagno, 1998; R. C. Martin \& Lesch, 1996; R. C. Martin, Lesch, \& Bartha, 1999). This would allow for phonological errors in ISR but not necessarily in word production. A simpler solution follows from the fact that even minimal semantic impairment produces considerable levels of anomia (Lambon Ralph, McClelland, Patterson, Galton, \& Hodges, 2001) in which no element of the target words' phonology appears to be activated; in these circumstances, it is not possible to make a phonological error. SD patients can, however, make these errors in ISR and delayed repetition tasks because the examiner gives the target phonology.

The semantic binding hypothesis fits well with studies of normal participants that suggest a role for semantics in ISR. Immediate recall improves when items are grouped by semantic category (Poirier \& Saint-Aubin, 1995), recall is better for concrete than for abstract words (Walker \& Hulme, 1999), and recall is higher for words that are easy to form a mental image of (Bourassa \& Besner, 1994). Although it is widely accepted that semantic representations can contribute to verbal STM, this semantic support is not universally regarded as being essential. According to the "redintegration" account of these findings, for example, the phonological STM trace becomes degraded over the course of ISR tasks but can be reconstructed from stable phonological lexical representations (Hulme, Maughan, \& Brown, 1991; Hulme, Roodenrys, Schweickert, Brown, Martin, \& Stuart, 1997; Schweickert, 1993). Semantic activation has been proposed to constrain the number of lexical representations that are considered as targets in this reconstructive process (Poirier \& Saint-Aubin, 1995), suggesting an indirect, nonessential, and late semantic contribution to STM. In contrast, Patterson et al. (1994) propose that the role of semantics is fundamental; verbal STM is seen as an emergent property of the semantic and phonological systems working together, and when semantic support is removed, the phonological coherence of items is necessarily disrupted.

Although SD patients can show superior recall of words that they still understand relatively well compared with more semantically degraded words, there have been some notable failures to find such differences (Funnell, 1996; Lambon Ralph \& Howard, 2000; McCarthy \& Warrington, 1987, 2001; Warrington, 1975). These appear to challenge Patterson et al.'s (1994) assertion that semantics makes an essential contribution to the phonological coherence of words in STM. Knott et al. (1997) did not find a significant recall difference between known and degraded words in one patient, BM, despite finding such a difference in a second patient, AM, and suggested that AM may have had co-morbid phonological or lexical impairments in addition to his primary semantic deficits, that accounted for his poor ISR. McCarthy and Warrington (2001) similarly argued that verbal STM can operate without the involvement of semantics and that additional non-semantic impairments are responsible for the recall differences between known and degraded words observed in some studies. It is important to note, however, that in all of these studies, the SD patients made frequent phonological errors in ISR even if they failed to show a recall advantage for known words, suggesting a strong association between semantic impairment and the integrity of representations in phonological STM. In addition, methodological factors (e.g., set size and the methods used to select known and degraded 
items) can influence the size of the knowndegraded recall difference. Most patients show superior recall of known words when set size exceeds about 20 items (Jefferies et al., in press) although it is not clear if differences in methodology can account for all of the variation between SD patients in previous studies.

The primary aim of this paper is to address the issue of whether additional phonological or lexical deficits should be invoked to account for the pattern of phonological errors made by SD patients in ISR. On the face of it, the association between semantic impairment and phonological errors in ISR appears to provide strong support for the semantic binding hypothesis and the related assertion that semantics plays a crucial role in ISR. The possibility that SD patients' phonological errors in ISR result from additional phonological or lexical impairments, however, undermines both of these claims.

The question of whether phonology is intact in SD remains largely neglected, despite its importance. Certainly, SD patients very rarely make phonological errors in spontaneous speech or picture naming (Patterson \& Hodges, 2000; Snowden, Griffiths, \& Neary, 1994), suggesting that they do not have problems with assembling the phonological elements of single words. Intact performance has been reported for a few patients on phoneme discrimination tasks like minimal pairs (detecting that two phonologically similar words-e.g., cup/cut-are different), phoneme segmentation tasks (requiring phonemes to be added to or deleted from words), and rhyme generation (Knott et al., 1997, 2000). In addition, SD patients have normal digit span abilities (Jefferies, Patterson, Jones, Bateman, \& Lambon Ralph, 2004; Warrington, 1975), and digit span remains relatively stable in the face of marked semantic decline (Knott et al., 2000). Moreover, a few patients have been shown to exhibit normal effects of phonological similarity in ISR (Knott et al., 2000; McCarthy \& Warrington, 2001), suggesting that verbal STM in SD relies heavily on a phonological code, as it does in healthy individuals. Normal effects of word length in ISR have also been demonstrated (Knott et al., 1997, 2000), although not for every patient tested (McCarthy \& Warrington, 2001).

Some aspects of the ISR performance of SD patients, however, raise doubts about the integrity of the phonological system. First, SD patients have been shown to exhibit little effect of recency in their serial position curves (Knott et al., 1997), a pattern that is associated with phonological impairments in aphasic populations (N. Martin \& Saffran, 1997). Second, ISR in SD appears to be strongly influenced by word frequency and imageability (Knott et al., 1997, 2000; McCarthy \& Warrington, 2001), even though lexical and semantic effects in ISR are generally reduced in patients who show deficits in semantic processing and/or the retention of semantic information (N. Martin \& Saffran, 1997; R. C. Martin \& Lesch, 1996; R. C. Martin, Shelton, \& Yaffee, 1994). In contrast, these effects are typically enhanced in patients with phonological impairments (N. Martin \& Saffran, 1997). Third, Knott et al. (1997) demonstrated that patient AB exhibited rapid phonological decay of single words in a delayed repetition paradigm when the delay was filled with counting. Last, Knott et al. (1997) obtained some evidence of a nonword repetition deficit in $\mathrm{AB}$. This patient showed a reduction of the normal lexicality effect in ISR, suggesting that his recall was more impaired for words than for nonwords. $\mathrm{AB}$ was, however, only able to repeat 28/40 multisyllabic nonwords (Children's Test of Nonword Repetition; Gathercole, Willis, Baddeley, \& Emslie, 1994), a score that would be impaired for 9-year-old children. Similarly, his recall of single syllable nonword sequences was right at the bottom of the normal range and was quite possibly impaired relative to his premorbid abilities.

None of these findings necessarily points to additional phonological or lexical deficits in SD. The lack of a recency effect could occur because semantic deficits impact most heavily on the phonological integrity of items at the end of lists. The phonological representations of these words may become particularly noisy in the absence of semantic support because they must be maintained for longer and during the production of other potentially interfering items. Hulme et al. 
(1997) found larger effects of word frequency in the recency portion of the serial position curve for normal participants, in line with this suggestion. The delayed single word repetition results of Knott et al. (1997) could be interpreted in the same way as the ISR differences between known and degraded words, namely, as a loss of semantic binding. The items were not selected according to patient AB's knowledge of them but they were probably partially semantically degraded. Consequently, AB may have been unable to sustain their phonology during the distraction task because of this reduced semantic support. In addition, strong effects of frequency may arise in SD because lower-frequency words generally degrade earlier in this condition than more frequent items (Funnell, 1995).

Although nonword recall is thought to be a purer measure of phonological STM than word recall because it involves unfamiliar phonological forms (Gathercole et al., 1994), word knowledge does appear to contribute to nonword ISR. Nonword recall is affected by "wordlikeness," that is, the degree to which nonwords are rated as being similar to words (Gathercole, 1995; Gathercole, Willis, Emslie, \& Baddeley, 1991). This wordlikeness effect may be underpinned both by sublexical factors like phonotactic frequency (Gathercole, Frankish, Pickering, \& Peaker, 1999; Gathercole \& Martin, 1996) and by lexical factors such as the number of real-word phonological neighbours a nonword has. Recent research suggests that the lexical contribution to nonword recall may be stronger than the sublexical one (Bailey \& Hahn, 2001; Roodenrys \& Hinton, 2002). By extension, nonword repetition impairments in SD could be underpinned by deficits in word knowledge rather than by impairments of phonology per se. One possibility, suggested by Knott et al. (1997), is that abnormal nonword repetition results from lexical impairments that are independent of these patients' primary semantic deficits. This suggestion concurs with the commonsense view that semantic factors do not impact on nonword recall, as these stimuli are basically meaningless. However, the PDP framework (Patterson et al., 1994; Plaut \& Kello, 1999) might predict an effect of semantic impairment on nonword repetition. If phonology is considered to emerge from the interactions between speech input, articulation and semantics (Plaut \& Kello, 1999), then phonological space is established in a semantic context. It follows from this that semantic degradation will have a considerable impact on the operation of the phonological system, as it will change the nature of the phonological space.

In this study, we examined the performance of six SD patients and matched controls on a range of phonological processing measures in order to evaluate the claim that the phonological system is unimpaired in this condition. Next, the effects of phonological similarity and word length on ISR were compared for the two groups to establish whether SD patients show the normal hallmarks of phonological coding in verbal STM. Nonword repetition and recall were tested, providing a means of assessing the contributions of phonology and semantics to ISR. We also examined the patients' recall of relatively well-known and semantically degraded words to determine whether a recall advantage for known words could emerge in the absence of additional phonological deficits. Finally, we investigated the patients' recall of nonwords constructed from these known and degraded words in order to explore the contention that semantics contributes to nonword recall.

\section{CASE DESCRIPTIONS}

This work examined six SD patients, who are described in order of severity. As all the cases exhibited similar patterns of deficits, the details given for the first patient can be assumed to apply to every case unless otherwise stated. A summary of the background neuropsychological assessment is shown in Table 1 . SJ, the patient with the mildest semantic impairments in this study, was a 60-year-old right-handed woman who had been experiencing worsening word-finding difficulties for approximately 3 years. She left school aged 16 and was working part-time as an antiques dealer at the time of the study. Her neuropsychological profile was dominated by a mild impairment of 
Table 1. Background neuropsychological scores

\begin{tabular}{|c|c|c|c|c|c|c|c|c|c|}
\hline \multirow[b]{2}{*}{ Test } & \multirow[b]{2}{*}{$\operatorname{Max}$} & \multirow[b]{2}{*}{ SJ } & \multirow[b]{2}{*}{$B S$} & \multirow[b]{2}{*}{$E K$} & \multirow[b]{2}{*}{$K I$} & \multirow[b]{2}{*}{$J T$} & \multirow[b]{2}{*}{$G T$} & \multicolumn{2}{|c|}{ Controls } \\
\hline & & & & & & & & $M$ & $S D$ \\
\hline $\mathrm{MMSE}^{\mathrm{e}}$ & 30 & $23^{*}$ & 25 & 26 & $23^{*}$ & 25 & $22^{*}$ & $>24^{\mathrm{a}}$ & - \\
\hline Coloured Progressive Matrices ${ }^{f}$ & 36 & 34 & 30 & 33 & $21^{*}$ & 36 & 35 & - & - \\
\hline \multicolumn{10}{|l|}{ Digit span ${ }^{g}$} \\
\hline Forwards & - & 5 & 8 & 7 & 8 & 8 & 7 & $6.8^{\mathrm{b}}$ & $0.9^{\mathrm{b}}$ \\
\hline Backwards & - & 3 & 4 & 4 & 5 & 4 & 4 & $4.7^{\mathrm{b}}$ & $1.2^{\mathrm{b}}$ \\
\hline Spatial span: Forwards ${ }^{\mathrm{h}}$ & - & 6 & NT & 6 & 6 & 5 & 5 & $5-6^{c}$ & - \\
\hline \multicolumn{10}{|l|}{ Naming } \\
\hline Correct responses & 64 & $30^{*}$ & $29^{*}$ & $18^{*}$ & $15^{*}$ & $6^{*}$ & $11^{*}$ & $62.3^{\mathrm{b}}$ & $1.6^{\mathrm{b}}$ \\
\hline Omissions & - & 19 & 5 & 24 & 17 & 46 & 14 & - & - \\
\hline Descriptions & - & 9 & 10 & 9 & 9 & 2 & 21 & - & - \\
\hline Semantic errors & - & 5 & 12 & 5 & 14 & 9 & 3 & - & - \\
\hline Superordinate responses & - & 1 & 8 & 8 & 9 & 1 & 15 & - & - \\
\hline Word-picture matching & 64 & $59^{*}$ & $40^{*}$ & $39^{*}$ & $36^{*}$ & $34^{*}$ & $27^{*}$ & $63.7^{\mathrm{b}}$ & $0.5^{\mathrm{b}}$ \\
\hline \multicolumn{10}{|l|}{$\mathrm{PPT}^{\mathrm{i}} \mathrm{P}-\mathrm{C}$} \\
\hline Pictures & 52 & $48^{*}$ & $33^{*}$ & $30^{*}$ & $31^{*}$ & $35^{*}$ & $32^{*}$ & $51.1^{\mathrm{b}}$ & $1.1^{\mathrm{b}}$ \\
\hline Words & 52 & $42^{*}$ & $35^{*}$ & $35^{*}$ & $35^{*}$ & $31^{*}$ & $27^{*}$ & $51.2^{\mathrm{b}}$ & $1.4^{\mathrm{b}}$ \\
\hline Category fluency (8 categories) & - & $31^{*}$ & $45^{*}$ & $27^{*}$ & $27^{*}$ & $9^{*}$ & $11^{*}$ & $113.9^{\mathrm{d}}$ & $12.3^{\mathrm{d}}$ \\
\hline Letter fluency (F, A, S) & - & $23^{*}$ & $33^{*}$ & $27^{*}$ & $17^{*}$ & $17^{*}$ & $14^{*}$ & $44.2^{\mathrm{b}}$ & $11.2^{\mathrm{b}}$ \\
\hline Rey figure immediate copy ${ }^{j}$ & 36 & 33 & 33 & 36 & 35 & 34 & 33 & $34.0^{\mathrm{d}}$ & $2.9^{\mathrm{d}}$ \\
\hline \multicolumn{10}{|l|}{ VOSP } \\
\hline Incomplete letters & 20 & 20 & 19 & 20 & $8^{*}$ & 18 & 17 & $19.2^{\mathrm{b}}$ & $0.8^{\mathrm{b}}$ \\
\hline Dot counting & 10 & 10 & 10 & 9 & 10 & 9 & 10 & $9.9^{\mathrm{b}}$ & $0.3^{\mathrm{b}}$ \\
\hline Position discrimination & 20 & 20 & 19 & 20 & 19 & 18 & 20 & $19.8^{\mathrm{b}}$ & $0.6^{\mathrm{b}}$ \\
\hline Cube analysis & 10 & 10 & 10 & 10 & 10 & 10 & 9 & $9.7^{\mathrm{b}}$ & $2.5^{\mathrm{b}}$ \\
\hline
\end{tabular}

*Denotes abnormal performance; NT denotes not tested.

${ }^{a}$ Cutoff for normal performance; ${ }^{b}$ Control data from Bozeat, Lambon Ralph, Patterson, and Hodges (2002); ${ }^{\mathrm{c} N o r m a l ~ r a n g e ~ f o r ~ a g e-~}$ matched participants; ${ }^{\mathrm{d}}$ Control data from Hodges and Patterson (1995). ${ }^{\mathrm{e}}$ Mini-Mental State Examination (Folstein, Folstein, \&

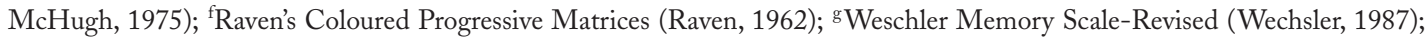
${ }^{\mathrm{h}}$ Weschler Memory Scale-III (Wechsler, 1997); ${ }^{\mathrm{P}}$ Pyramids and Palm Trees test (Howard \& Patterson, 1992); ${ }^{\mathrm{j}}$ Rey figure taken from Lezak (1976); ${ }^{k}$ Visual Object and Space Perceptual battery (Warrington \& James, 1991).

semantic memory. An MRI scan showed bilateral temporal lobe atrophy that was more marked in the left hemisphere. She was impaired on tests requiring comprehension of words and pictures; for example, a word-picture matching task that required patients to select a target item from a set of 10 semantically related distracters, and the Pyramids and Palm Trees test (Howard \& Patterson, 1992). She was anomic in spontaneous speech, word fluency tasks, and confrontational picture naming. Her naming errors were primarily omissions, descriptions, and semantic paraphasias (see Table 1). In common with other SD patients, she produced surface dyslexic errors in reading aloud and surface dysgraphic errors in spelling tasks. In contrast to her semantic difficulties, she was well oriented in time and place, had excellent episodic memory for recent events, and had no difficulty in remembering appointments. She performed normally on tests of visual-spatial processing from the Visual Object and Space Perception battery (VOSP; Warrington \& James, 1991), and she was able to produce a good immediate copy of the Rey complex figure (Lezak, 1976). Her nonverbal reasoning on the Coloured Progressive Matrices test (Raven, 1962) was normal. Her speech was fluent and syntactically well formed despite her anomia. She had intact single word phonology and she did not make phonological errors in her spontaneous speech or picture 
naming. She had normal spatial STM as assessed by the Corsi block tapping task, and normal verbal STM as measured by forwards and backwards digit span (Wechsler, 1987). Her word span performance, however, was characterised by frequent phonological errors similar to those described by Patterson et al. (1994).

BS was a 67-year-old right-handed man who left school aged 16 and had previously worked as a bookseller. He had been experiencing a gradual decline in semantic memory for around 4 years. He first reported difficulties in recognising the faces of acquaintances but by the time of the study he also experienced frequent word-finding difficulties. An MRI scan showed marked bilateral temporal lobe atrophy. His cognitive profile was similar to the description of SJ above although his semantic impairments were a little more severe.

EK was a 60-year-old right-handed woman who left school at the age of 15 and had been experiencing worsening word-finding difficulties for around 5 years. She was living alone and doing occasional cooking and cleaning jobs at the time of the study. An MRI scan showed bilateral temporal lobe atrophy that was more marked in the left hemisphere. Her semantic impairments were moderately severe at the time of the study, but in contrast, her single word phonology, visual spatial processing, nonverbal reasoning, and episodic memory for recent events were largely intact.

KI was a 65-year-old right-handed man, who left school aged 14 and had previously worked in heavy engineering. He had a 4-year history of worsening semantic impairments. He was severely impaired on both verbal and pictorial tests of semantic memory although, unusually, he exhibited greater deficits on pictorial tests. He had considerable difficulties recognising objects and faces and he was severely anomic in spontaneous speech, word fluency tasks, and confrontational picture naming. In contrast, he had good visual spatial processing and episodic memory for recent events. He showed some weakness, however, in a test of nonverbal reasoning. He also exhibited some behavioural changes, including disinhibition, which would be consistent with the disease process affecting basal frontal as well as temporal regions (Snowden et al., 1996).

JT, a 66-year-old right-handed male who left school at 16 , was running a small farming business at the time of the study. He had been experiencing worsening word-finding difficulties for 4 years. An MRI scan showed significant temporal lobe atrophy that was considerably more marked on the left side. He was severely impaired on a range of pictorial and verbal tests of semantic memory and his picture naming performance was approaching floor. However, his single word phonology, visualspatial skills, nonverbal reasoning abilities, and memory for recent events were largely intact.

GT, a 71-year-old right-handed male, was a retired builder and college technician who left school aged 14 . He had been experiencing a gradual decline in word finding and comprehension for 5 years. An MRI scan showed marked bilateral circumscribed temporal lobe atrophy. GT was severely impaired on a range of pictorial and verbal tests of semantic memory, and his speech was characterised by anomia and circumlocutions, although it remained fluent, syntactically well formed, and free from phonological errors. His visual-spatial skills, nonverbal reasoning abilities, and memory for recent events were largely intact. His hearing was slightly impaired in his right ear.

\section{PHONOLOGICAL PROCESSING ABILITIES}

The six patients were tested on a variety of tasks thought to tap phonological processing skills. First, they were given the minimal pairs tests from the PALPA battery (Kay, Lesser, \& Coltheart, 1992). They were tested on two parallel tasks involving CVC (consonant vowel consonant) words and nonwords. Both tasks required the patients to detect that two phonologically similar items (e.g., "gut" and "cut") were different. There were 36 "no change" trials and 36 "change" trials in each test. Stimulus pairs were minimally different according to position (initial phoneme, final phoneme, or metathetic differences in which the initial and final phonemes were exchanged) and type of 
change (voicing, manner, or place of articulation). There were equal numbers of each type of change.

The patients were also given a phoneme segmentation task (from Patterson \& Marcel, 1992) that required phonemes to be deleted from and added to the beginning of words and nonwords. In the phoneme addition task, the examiner read a word like "old" and asked the patient to join the sound "g" onto the beginning, to make "gold." In the phoneme deletion task, the examiner presented "gold" and asked the patient to take away the first sound, leaving "old." There were 48 trials of each type, blocked using an ABBA design. Within each block of 24 trials, there were 6 trials in which the patient was given a word and had to produce a second word in response ("old" into "gold"). In a further six trials, the stimulus was a word and the patient had to produce a nonword ("shave" into "ayve"). In six more trials, the stimulus was a nonword and the patient had to produce a word ("pice" into "ice"), and in the final six trials, the stimulus and target were both nonwords ("vaf" into "aff"). These four conditions were presented in a mixed fashion. Patients practised the task until it was clear that they understood it.

In a further test of their phonological processing abilities, the patients were given rhyme judgement and production tasks (from Patterson \& Marcel, 1992). In the rhyme judgement task, the patients were presented with pairs of words like "fall-call" and were asked to decide if the pairs rhymed. There were 48 pairs in total, comprising an equal number of rhyming and nonrhyming pairs. The words in the nonrhyming pairs were either phonologically similar or dissimilar. In the rhyme production task, 24 words were read aloud, and for each one the patient was asked to think of a word that rhymed with it. These rhyme tests had to be abandoned for GT, as he was unable to understand the test instructions, despite being given numerous examples of rhyming and nonrhyming words.

\section{Results}

Table 2 gives the patients' scores on these tests of phonological processing. The patients with the mildest semantic impairments, SJ and BS, performed normally on the minimal pairs and phoneme segmentation tasks but showed some weakness on the rhyme judgement and production tasks. They were able to think of rhyming words for the majority of items in the rhyme production test but they deviated from the normal pattern by sometimes producing rhyming nonwords. In the rhyme judgement task, they showed a tendency to accept phonologically similar words as rhymes, perhaps because they did not fully comprehend the notion of rhyme.

EK and KI, who were rather more severely semantically impaired, also performed normally on the minimal pairs task but exhibited some impairment of phoneme segmentation. They tended to make phonological errors on this task (e.g., "n" added to "oath" produced as "note" and not "noath"). In many of these errors, the phoneme of interest was added or subtracted correctly but errors occurred in other parts of the target. As the memory load in the segmentation task was considerable, these errors may have reflected the impact of the patients' semantic deficits on the coherence of items in phonological STM. In line with this suggestion, the patients were more impaired on the addition than the subtraction version of the task, perhaps because the addition version required simultaneous maintenance of both the item and the phoneme to be added and therefore made greater STM demands. Alternatively, the addition task may have been more demanding because it required subtraction of the neutral schwa sound from the phoneme to be added as well as phoneme addition. It is also worth noting that $6 / 15$ of EK's errors involved the "sh" phoneme. She appeared to be using a letter-spelling strategy (add or take away initial letter) that failed for this multiletter phoneme and resulted in errors in the subtraction task like "hade" for "shade," instead of "aid." JT, who had a more severe semantic impairment than EK and KI, did not show this weakness in the phonological segmentation task but was more substantially impaired in the rhyme production task.

The patient with the most severe semantic deficits in this study, GT, showed considerable weakness in all of these tests of phonological processing. First, he was the only patient to show a

\section{COGNITIVE NEUROPSYCHOLOGY, 2005, 22 (2)}


Table 2. Performance on tests of phonological processing

\begin{tabular}{|c|c|c|c|c|c|c|c|c|}
\hline Test & $\operatorname{Max}$ & $\begin{array}{c}\text { Control } \\
\text { Mean (SD) }\end{array}$ & SJ & $B S$ & $E K$ & $K I$ & $J T$ & $G T$ \\
\hline \multicolumn{9}{|l|}{ Minimal pairs ${ }^{\mathrm{b}}$} \\
\hline Words (same) & 36 & $35.54(0.78)$ & 36 & 35 & 36 & 36 & 36 & 35 \\
\hline Words (different) & 36 & $34.54(2.58)$ & 36 & 36 & 35 & 33 & 34 & 29 \\
\hline Nonwords (same) & 36 & $35.79(0.56)$ & 34 & 35 & 36 & 36 & 36 & 35 \\
\hline Nonwords (different) & 36 & $35.09(2.34)$ & 36 & 36 & 35 & 35 & 34 & $25^{*}$ \\
\hline \multicolumn{9}{|l|}{ Phoneme segmentation } \\
\hline Addition & 48 & a & 45 & 48 & $37^{*}$ & $38^{*}$ & 44 & $32 *$ \\
\hline Subtraction & 48 & a & 47 & 48 & 44 & 45 & 46 & $34^{*}$ \\
\hline \multicolumn{9}{|l|}{ Rhyme judgement } \\
\hline Total correct & 48 & a & $43^{*}$ & 46 & $42^{*}$ & $40^{*}$ & 46 & - \\
\hline Nonrhyming phonologically similar pairs & 12 & a & 8 & 10 & 6 & 7 & 12 & - \\
\hline Correct real-word responses & 24 & a & $21^{*}$ & 23 & $20^{*}$ & $20^{*}$ & $17^{*}$ & - \\
\hline All rhyming responses & 24 & a & 22 & 24 & 23 & 23 & $20^{*}$ & - \\
\hline
\end{tabular}

*Denotes abnormal performance.

${ }^{a}$ Controls perform at ceiling on these tasks (Bird, Lambon Ralph, Seidenberg, McClelland, \& Patterson, 2003).

${ }^{b}$ From the PALPA battery (Kay et al., 1992).

deficit on the minimal pairs tests. His "same" judgements were normal, but he was poor at discerning when two items were different, particularly for nonwords. His performance on word stimuli was right at the bottom of the range of scores expected for healthy participants and his performance on nonwords was more substantially outside the normal range. Therefore, although the difference between words and nonwords did not reach significance, $\chi^{2}(1)<1$, there was some suggestion of a lexicality effect in his performance on this task. Combining across words and nonwords, GT's performance was substantially affected by whether the pairs were minimally different according to voice, manner, or place of articulation, $\chi^{2}(2)=40.44$, $p<.0001$. He detected $24 / 24$ differences in voicing, 23/24 differences in manner, but only $7 / 24$ differences in place of articulation. GT also exhibited the most substantial impairment on the phonological segmentation test observed in this group of patients. When the results from the addition and subtraction versions of the test were combined, he showed a significant effect of lexicality, $\chi^{2}(2)=$ 9.01, $p<.05$. He was better able to perform the task when both the stimulus and target were real words (19/24) than when they were both nonwords $(13 / 24)$. He showed an intermediate level of performance when the stimulus was a word and the target a nonword (16/24), and when the stimulus was a nonword and the target a word (18/24). These two categories were combined in the chisquare analysis.

\section{Discussion}

The patients' performance was not entirely intact on these tasks of phonological processing, although their poor performance might have resulted from their primary semantic impairments and not from any additional phonological deficits. There appeared to be an association between semantic impairment and poor phonological processing, as the most semantically impaired patients in this study also showed the poorest performance on these tasks. There are, however, two plausible explanations of this relationship. First, the temporal lobe atrophy that characterises SD may encroach on phonological as well as semantic areas as the condition progresses. Alternatively, if semantics plays a major role in the coherence of phonological representations, as suggested by the semantic binding hypothesis (Patterson et al., 1994), then the degree of semantic impairment should impact on performance in these tasks even in the absence 
of an additional phonological impairment. The phoneme segmentation, minimal pairs, and rhyme judgement tasks all require accurate phonological representations to be maintained. In addition, GT showed an influence of lexicality in his segmentation and minimal pairs performance. Although this result suggests that these tasks may be influenced by the integrity of the semantic system, it is also possible that GT showed a lexical-semantic influence precisely because he had a phonological processing deficit. Lexical-semantic effects may become exaggerated when the phonological system is impaired. Clearly, the patients' performance on these phonological processing tasks cannot be interpreted unambiguously. For this reason, we examined the effect of phonological similarity and word length on the patients' ISR, as these welldocumented effects are thought to be the hallmarks of normal phonological STM and articulatory rehearsal respectively (e.g., Vallar \& Papagno, 2002).

\section{THE EFFECT OF PHONOLOGICAL SIMILARITY ON IMMEDIATE SERIAL RECALL}

Verbal STM in healthy individuals is poorer for similar sounding items compared with phonologically more distinct items. This "phonological similarity effect" is usually taken as evidence for phonological coding in verbal STM (Baddeley, 1966; Conrad, 1964; Conrad \& Hull, 1964). Therefore, a normal effect of phonological similarity in patients with SD would be consistent with intact phonological coding in verbal STM.

\section{Method}

The patients and 12 control participants were asked to recall 40 lists composed of letters from the phonologically similar set E, C, T, P, V, B, G, $\mathrm{D}$ or the phonologically dissimilar set $\mathrm{W}, \mathrm{S}, \mathrm{Q}, \mathrm{Y}$, R, J, F, L, following Knott et al. (2000). Half of the lists contained four items and half contained six items. The phonologically similar and dissimilar letters were blocked using an ABBA design. In this and subsequent ISR experiments, items were read aloud at a rate of one item per second for spoken recall. The controls in every experiment were matched to the patients for age and educational level. They reported that they had normal hearing and spoke English as a first language.

\section{Results}

Recall accuracy. Table 3 gives the number of phonologically similar and dissimilar letters that were correctly recalled by the patients and controls. The data were first analysed using an analysis of variance (ANOVA) comprising two withinsubject factors (phonological similarity and list length) and one between-subject factor (group: patients versus controls). As the results were similar for item and list recall, only item recall is discussed here. There were significant effects of phonological similarity, $F(1,16)=45.93, p<.0001$, and list length, $F(1,16)=109.66, p<.0001$. The main effect of group was not significant, $F(1,16)<1$, suggesting that letter recall was not greatly impaired in the patients. There was also no evidence of a phonological similarity by group interaction, $F(1,16)=1.67, n s$, suggesting that the magnitude of the phonological similarity effect did not differ very substantially for the patients and controls. No other interactions reached significance.

Considering each patient individually, letter recall fell within the normal range for every patient tested except KI, who showed a mild weakness in some conditions (see Table 3). KI was the only patient in this group who was impaired at naming incomplete letters in the VOSP test battery (Warrington \& James, 1991: see Table 1), suggesting that his immediate recall deficits for letters may have been underpinned by degraded knowledge of letters. SJ showed a significant phonological similarity effect, $t(37)=3.28, p<.01$, as did BS, $t(32)=2.93, p<.01$, and $\mathrm{EK}, t(35)=3.33, p<.01$. In contrast, the three more severely impaired patients did not exhibit a significant phonological similarity effect: KI and JT, $t(37)<1$; GT, $t(35)<1$. It is important to note, however, that the magnitude of the phonological similarity effect was very variable in the control participants, and while 
Table 3. Recall of phonologically similar and dissimilar letters

\begin{tabular}{|c|c|c|c|c|c|c|c|c|c|}
\hline & List length & $N$ & SJ & $B S$ & $E K$ & $K I$ & $J T$ & $G T$ & Control mean (range) \\
\hline \multicolumn{10}{|l|}{ Items (\%) } \\
\hline Dissimilar & 4 & 40 & 97.5 & 97.5 & 100.0 & 95.0 & 90.0 & 90.0 & $96.5(85-100)$ \\
\hline Similar & 4 & 40 & 70.0 & 87.5 & 90.0 & 95.0 & 92.5 & 85.0 & $82.7(63-98)$ \\
\hline Difference & 4 & & 27.5 & 10.0 & 10.0 & 0.0 & $-2.5^{*}$ & 5.0 & $13.8(0-35)$ \\
\hline Dissimilar & 6 & 60 & 73.3 & 85.0 & 86.7 & $70.0^{*}$ & 71.7 & 81.7 & 83.8 (72-97) \\
\hline Similar & 6 & 60 & 65.0 & 63.3 & 70.0 & 61.7 & 71.7 & 75.0 & $70.1(53-82)$ \\
\hline Difference & 6 & & 8.3 & 21.7 & 16.7 & 8.3 & $0.0^{*}$ & 6.7 & $13.6(5-23)$ \\
\hline \multicolumn{10}{|l|}{ Lists (\%) } \\
\hline Dissimilar & 4 & 10 & 90 & 90 & 100 & 80 & 60 & 70 & $88.3(50-100)$ \\
\hline Similar & 4 & 10 & 10 & 60 & 60 & 80 & 70 & 40 & $50.0(10-80)$ \\
\hline Difference & 4 & & 80 & 30 & 40 & 0 & $-10^{*}$ & 30 & $38.3(0-90)$ \\
\hline Dissimilar & 6 & 10 & 10 & 40 & 50 & $0^{*}$ & 30 & 20 & $40.0(10-80)$ \\
\hline Similar & 6 & 10 & 0 & 10 & 0 & 0 & 0 & 20 & $8.3(0-40)$ \\
\hline Difference & 6 & & 10 & 30 & 50 & $0^{*}$ & 30 & $0^{*}$ & $31.7(10-50)$ \\
\hline
\end{tabular}

*Denotes abnormal performance.

every control showed a numeric advantage for dissimilar items, this did not always reach significance, $t(25-38)=4.63$ to $<1, p<.0001$ to $n s$. These analyses combined across list length, although the pattern of results did not change if the longer lists were considered separately. The size of the phonological similarity effect in item recall was within the normal range for every patient except JT, who showed a slight numerical advantage for phonologically similar items on the shorter list length. None of the controls showed a difference in this direction, although their recall was constrained by ceiling effects. On the longer lists, the size of JT's phonological similarity effect was again outside the normal range for item recall, but was more normal for list recall. On the whole, the patients showed effects of phonological similarity that were within the normal range. Further discussion of these findings will be postponed until after the next experiment, which considers the effect of word length on ISR.

\section{THE EFFECT OF WORD LENGTH ON IMMEDIATE SERIAL RECALL}

Healthy participants are able to recall a larger number of short than long words in verbal STM. This "word length effect" has been variously attributed to a time-based rehearsal process used to reinstate the phonological trace as it decays (Baddeley, Lewis, \& Vallar, 1984; Baddeley, Thomson, \& Buchanan, 1975), to decay during speech output delays (Cowan, Day, Saults, Kellar, Johnson, \& Flores, 1992), and to phonological complexity, as longer words are generally also more complex (Service, 1998). Although there is still controversy about the underlying cause of the word length effect, it is considered to be one of the characteristic features of phonological STM and therefore it might be expected to remain intact in $\mathrm{SD}$ if the integrity of the phonological system is unaffected by this condition.

\section{Method}

Five patients and 12 control participants were included in this experiment. BS was not tested due to time constraints. Forty three-syllable words containing between 6 and 11 phonemes $($ mean $=7.5)$ and 40 monosyllabic words containing between 2 and 4 phonemes (mean $=3.1)$ were selected. The two sets of words were matched closely on an itemby-item basis for word frequency (using data from Kucera \& Francis, 1967; mean frequency long words $=91.8$, short words $=91.0$ ) and were assembled into lists of four items, yoked so that frequency-matched words appeared in the same positions in the lists for long and short words. 
Twenty lists of each word type were presented in a blocked fashion using an ABBA design.

\section{Results}

Recall accuracy. Table 4 shows the number of items and lists recalled correctly for long and short words. Item recall was analysed using an ANOVA incorporating a within-subjects factor (word length) and a between-subjects factor (group: patients vs. controls). There were significant main effects of word length, $F(1,15)=24.04, p<.001$, and group, $F(1,15)=42.55, p<.0001$. There was no evidence of an interaction between these factors, $F(1,15)<1$, suggesting that the effect of word length did not differ greatly for the patients and controls. The patients' recall was generally below the normal range, particularly for the short words, because they made numerous phonological errors on both sets of items. EK recalled significantly more short than long items, $t(38)=3.29$, $p<.01$, as did KI, $t(37)=2.65, p<.05$. SJ, JT, and GT did not show any significant effects of word length: SJ, $t(38)<1$; JT, $t(37)<1.36, n s$; GT, $t(37)<1$. As in the previous experiment, however, the effect of word length was very variable in the controls and did not always reach significance, $t(25-38)=5.86$ to $<1, p<.0001$ to n.s. The size of the word length effect was within the control range for every patient. Although the short and long words were not closely matched for imageability (503 vs. 407 on a scale of 100-700, using data from Bird, Franklin, \& Howard, 2001; and Coltheart, 1981), the same pattern of results was apparent for a subset of the lists that were matched on this variable.

Recall errors. The influence of word length on the patients' errors was examined to cast further light on the processes underlying the word length effect. Incorrect responses were classified as phonological if they contained at least half of the phonemes present in a target word. Other errors, e.g., omissions, order errors, repetitions and intrusions of items from previous lists, were classified as non-phonological. Table 5 shows the number of

Table 4. Recall of long and short words

\begin{tabular}{lccccccc}
\hline & $N$ & $S J$ & $E K$ & $K I$ & $J T$ & $G T$ & Control mean (range) \\
\hline Items (\%) & & & & & & & \\
Short & 80 & $63.8^{*}$ & $77.5^{*}$ & $77.5^{*}$ & $66.3^{*}$ & $57.5^{*}$ & $91.3(83-99)$ \\
Long & 80 & 56.3 & $51.3^{*}$ & 58.8 & 55.0 & $53.8^{*}$ & $77.7(55-89)$ \\
Difference & & 7.5 & 26.3 & 18.8 & 11.3 & 3.8 & $13.5(3-34)$ \\
Lists (\%) & & & & & & & \\
Short & 20 & $25^{*}$ & 45 & 35 & 30 & $5^{*}$ & $70.4(30-95)$ \\
Long & 20 & 15 & 10 & 10 & 5 & 15 & $41.7(5-65)$ \\
Difference & & 10 & 35 & 25 & 25 & -10 & $28.8(-20-60)$ \\
\hline
\end{tabular}

*Denotes abnormal performance.

Table 5. Errors on long and short words

\begin{tabular}{lcccccc}
\hline & $S J$ & $E K$ & $K I$ & $J T$ & $G T$ & Control mean (range) \\
\hline Short & & & & & & \\
Phonological & $25^{*}$ & $11^{*}$ & $15^{*}$ & $26^{*}$ & $22^{*}$ & $2.9(0-8)$ \\
Non-phonological & 4 & 7 & 3 & 1 & $12^{*}$ & $4.1(0-8)$ \\
Long & & & & & & \\
Phonological & $16^{*}$ & $11^{*}$ & $23^{*}$ & $20^{*}$ & $16^{*}$ & $3.1(1-5)$ \\
Non-phonological & 19 & 28 & 10 & 16 & 21 & $14.8(6-33)$ \\
\hline
\end{tabular}

*Denotes abnormal performance. Figures denote total errors on 40 items.

\section{COGNITIVE NEUROPSYCHOLOGY, 2005, 22 (2)}


phonological and non-phonological errors for patients and controls on short and long words. The patients made roughly normal numbers of nonphonological errors but inflated numbers of phonological errors that fell outside the control range, for both long and short words. Increases in word length were predominantly associated with increases in non-phonological but not phonological errors, for both patients and controls. Consequently, the balance of phonological to non-phonological errors varied across short and long words for SJ, $\chi^{2}(1)=9.61, p<.01$, EK, $\chi^{2}(1)=4.32, p<.05$, and JT, $\chi^{2}(1)=11.01$, $p<.001$. This error difference between short and long words did not reach significance for GT, $\chi^{2}(1)=2.48$, ns or KI, $\chi^{2}(1)<1$. The finding that word length predominately affected the occurrence of non-phonological rather than phonological errors is consistent with the view that the verbal STM capacity of the SD patients was exceeded by the long words in a relatively normal way.

\section{Discussion}

Most of the patients exhibited effects of phonological similarity and word length in ISR that were within the normal range, consistent with them having normal phonological coding and rehearsal processes in verbal STM. It remains possible that phonological similarity and word length effects are slightly reduced in size in SD patients on average, although we did not find conclusive evidence of this in the performance of individual patients. The word length effect in the patients appeared to result from a normal increase in the number of non-phonological errors on the longer words. Interestingly, word length did not affect the number of phonological errors committed by the patients. Therefore, it seems that although the patients had difficulty maintaining the phonological integrity of the words in STM, the amount of phonological material to be recalled did not increase the likelihood of phonological breakdown.

\section{REPETITION OF SINGLE MULTISYLLABIC NONWORDS}

The patients and 10 controls matched for age and educational level were tested on the Children's Test of Nonword Repetition (CN Rep; Gathercole et al., 1994), in order to investigate the suggestion that nonword repetition is impaired in SD. This test involves the immediate repetition of 40 nonwords, ranging in length from two to five syllables. Table 6 shows the scores obtained by the patients and controls. The five mildest patients, SJ, BS, $\mathrm{EK}, \mathrm{KI}$, and JT, were able to repeat the majority of items correctly, whereas GT showed some weakness on this test. It is important to note, however, that the performance of the controls was highly variable. Most of the controls made very few errors but several controls performed surprisingly poorly. The patients were within the normal range with the exception of GT, whose performance fell slightly below the poorest control score. GT showed little effect of item length and made an unusually large number of errors on the short items.

In summary, the results of the CN Rep test suggest that nonword repetition was largely intact in these SD patients, although the patient with the severest semantic deficit was mildly impaired. Interestingly, the performance of Knott et al.'s (1997) patient, AB, did not fall below the range of scores obtained for our control participants,

Table 6. Scores on the CN Rep test (Gathercole et al., 1994)

\begin{tabular}{lcccccccc}
\hline & Max & SJ & BS & $E K$ & $K I$ & $J T$ & $G T$ & $\begin{array}{c}\text { Control median } \\
\text { score (range) }\end{array}$ \\
\hline Total & 40 & 35 & 36 & 38 & 32 & 28 & $21^{*}$ & $35(23-39)$ \\
Short items (2-3 syllables) & 20 & 18 & 19 & 20 & 18 & 19 & $9^{*}$ & $19(14-20)$ \\
Long items (4-5 syllables) & 20 & 17 & 17 & 18 & 14 & 9 & 12 & $17(8-19)$ \\
\hline
\end{tabular}

*Denotes abnormal performance. 
although his performance may have been impaired in comparison with his premorbid abilities. We examined STM for nonwords in more detail in the following experiment, which required lists of monosyllabic nonwords to be recalled in order.

\section{SERIAL RECALL OF MONOSYLLABIC NONWORD LISTS}

\section{Method}

The 6 patients and 10 control participants were asked to recall lists of monosyllabic CVC nonwords and words (taken from Gathercole, Pickering, Hall, \& Peaker, 2001). The words were not selected according to the patients' knowledge of them. The patients were tested on lists containing two to four items and the controls were additionally tested on five-item lists. There were 20 lists at each length, divided equally between the two materials. The words and nonwords, which were not repeated in the course of the experiment, were blocked using an ABBA design and were presented auditorily at a rate of one item per second for immediate serial recall.

\section{Results}

Recall accuracy. Table 7 shows the number of words and nonwords recalled by the patients and controls at each list length. The data were analysed using an ANOVA incorporating two withinsubjects factors (list length and lexicality) and one between-subjects factor (group: patients vs. controls). The main effect of group approached significance, $F(1,14)=3.92, p=0.07$. There were significant main effects of both lexicality, $F(1,14)=138.75, p<.0001$, and list length, $F(2,28)=97.54, p<.0001$, indicating that recall was better for the words than for the nonwords and that percentage recall declined as list length increased. The interaction between lexicality and group reached significance, $F(1,14)=8.96$, $p<.01$. The patients' recall was impaired for words but not nonwords: The controls recalled the words more accurately than the patients, but the recall of nonwords did not differ across the groups: planned comparisons; $t(8)=4.65, p<.01$ and $t(11)<1$ respectively. In addition, there were significant interactions between length and group, $F(2,28)=3.77, p<.05$, lexicality and length, $F(2,28)=6.45, p<.01$, and lexicality, length, and group, $F(2,28)=3.59, p<.05$. These interactions appeared to be caused by ceiling effects: The controls' recall of words but not nonwords was at ceiling on the shortest list length.

For every patient, word recall was below the normal range on some list lengths, whereas only GT's nonword recall fell below the normal range. Furthermore, all the patients showed some reduction in the size of the lexicality effect. For the controls, the recall difference between words and nonwords on four-item lists was between $60 \%$ and $28 \%($ mean $=42 \%)$. For the patients, the size of this difference was between $10 \%$ and $23 \%$ (mean $=$ $16 \%)$. A significant advantage for words over nonwords occurred for $\mathrm{KI}, t(76)=2.00, p<.05$,

Table 7. Percentage of single-syllable words and nonwords recalled by patients and controls

\begin{tabular}{lllrrrrrrc}
\hline List length & Word type & $N$ & $S J$ & $B S$ & $E K$ & $K I$ & $J T$ & $G T$ & Control mean(range) \\
\hline 2 & Words & 20 & 100 & 100 & 100 & $85^{*}$ & 95 & $80^{*}$ & $98(90-100)$ \\
& Nonwords & 20 & 90 & 95 & 100 & 65 & 75 & $45^{*}$ & $82(50-100)$ \\
3 & Words & 30 & 83 & 83 & 83 & 80 & $73^{*}$ & $73^{*}$ & $93(77-100)$ \\
4 & Nonwords & 30 & 43 & 67 & 77 & 53 & 47 & 47 & $57(27-83)$ \\
& Words & 40 & $43^{*}$ & $63^{*}$ & $65^{*}$ & $48^{*}$ & $40^{*}$ & $45^{*}$ & $81(70-98)$ \\
5 & Nonwords & 40 & 23 & 53 & 43 & 28 & 30 & 33 & $40(23-63)$ \\
& Words & 50 & - & - & - & - & - & - & $60(42-78)$ \\
& Nonwords & 50 & - & - & - & - & - & - & $20(8-36)$ \\
\hline
\end{tabular}

*Denotes abnormal performance. $N=$ number of items. 
and GT, $t(70)=2.41, p<.05$. The lexicality effect approached significance for SJ, $t(76)=1.88$, $p=.06$, and did not reach significance for $\mathrm{BS}$, $t(77)<1$, EK, $t(78)<1$, or JT, $t(74)=1.57, n s$, combining the data from different list lengths. Without exception, the control participants showed very substantial effects of lexicality, $t(51-72)=4.12-5.96, p<.001$.

Recall errors. Table 8 shows the types of errors that occurred for patients and controls on words and nonwords, combining across list lengths that all participants were tested on. Errors were categorised as being phonological if they contained at least half of the phonemes present in a target word. Omission errors occurred when fewer items were recalled than were presented. Order errors, repetitions of target items, and intrusions of items from previously presented lists occurred infrequently and were placed in a single category of "other" errors. Responses were placed in this category even if they also met the criterion for a phonological error. Incorrect responses that could not be categorised as order errors, repetitions, intrusions, or phonological errors were classified as unrelated. In reality, these errors generally did preserve some of the phonemes of the target items, although fewer than $50 \%$.

All of the patients made frequent phonological errors in word recall that fell outside the normal range, consistent with the view that semantics makes an important contribution to the coherence of items in STM. In contrast, the patients made far fewer errors in the other categories, and the frequency of these errors largely fell within the normal range. In nonword recall, the number of phonological errors was substantially larger for the controls and consequently, with the exception of $\mathrm{KI}$, the patients' errors in this category did not exceed the normal range.

An ANOVA was used to examine the numbers of phonological and non-phonological errors (including unrelated errors, omissions, and other errors) made by the patients and controls on words and nonwords. This analysis collapsed across list length: As the controls but not the patients were tested on lists of five items, errors were expressed as a proportion of the number of items presented. The three-way interaction between participant group, lexicality, and error type was significant, $F(1$, $14)=5.28, p<.05$. The controls showed a different balance of phonological to non-phonological errors for words and nonwords, $F(1,9)=32.60, p<.001$, whereas the patients did not, $F(1,5)=3.41$, ns. The controls made more phonological than nonphonological errors in nonword recall, $t(9)=4.41$, $p<.01$, but did not show this preponderance of phonological errors in word recall, $t(9)=-1.90$, ns. The patients, in contrast, made a greater number of phonological than non-phonological errors in their recall of both words, $t(5)=5.05, p<.01$, and nonwords, $t(5)=6.54, p<.01$.

In the word recall task, the controls showed a strong bias to produce real word responses when

Table 8. Errors on single-syllable words and nonwords

\begin{tabular}{lrrrrrrl}
\hline Errortype & $S J$ & $B S$ & $E K$ & $K I$ & $J T$ & $G T$ & Control mean (range) \\
\hline Words & & & & & & & \\
Phonological & $22^{*}$ & $13^{*}$ & $13^{*}$ & $27^{*}$ & $26^{*}$ & $28^{*}$ & $6.2(1-11)$ \\
Unrelated & $6^{*}$ & 1 & 4 & 3 & 4 & $5^{*}$ & $1.5(0-4)$ \\
Omission & 0 & 6 & 1 & 0 & 0 & 0 & $2.1(0-6)$ \\
Other & 0 & 0 & 1 & 0 & 3 & 1 & $0.3(0-1)$ \\
Nonwords & & & & & & & \\
Phonological & 38 & 24 & 24 & $43^{*}$ & 36 & 33 & $29.3(21-40)$ \\
Unrelated & 12 & 1 & 6 & 7 & 13 & 21 & $7.9(0-24)$ \\
Omission & 0 & 5 & 0 & 0 & 0 & 0 & $2.7(0-15)$ \\
Other & 0 & 0 & 0 & 0 & 0 & 0 & $0.8(0-7)$ \\
\hline
\end{tabular}

*Denotes abnormal performance. Table combines data from two-, three-, and four-item lists. Figures indicate total errors on 90 items. 
they made phonological errors (combining across participants, $88 \%$ of errors were real words). The patients showed this bias to a lesser extent (64\% of errors were real words) and, as a result, the balance of word to nonword responses in the word recall task was different for the patients and controls, $\chi^{2}(1)=19.82, p<.0001$. In the nonword recall task, the controls no longer showed a strong bias to produce real word responses (50\% of errors were real words) and the patients made a similar mix of word and nonword responses (44\% of errors were real words). Consequently, the balance of word to nonword responses did not differ between the patients and controls for nonword recall, $\chi^{2}(1)=1.55$, ns.

\section{Discussion}

The patients' repetition of single multisyllabic nonwords taken from the CN Rep test (Gathercole et al., 1994) was largely intact, as was their recall of strings of monosyllabic nonwords. In contrast, the patients' recall of real words was substantially impaired and was characterised by an abnormally large number of phonological errors, similar to those observed in previous studies (McCarthy \& Warrington, 1987; Patterson et al., 1994). Although these words were not selected according to the patients' understanding of them, it is likely that their comprehension was at least partly compromised, and therefore the phonological errors may have arisen because the semantic system was unable to constrain the phonological representations in STM in the normal way. Both the patients and the controls made a substantial number of phonological errors in their recall of nonwords, which by definition largely lack semantic support. The number of phonological errors made by the patients in nonword recall was for the most part within the normal range. However, there was some suggestion that the patients with the greatest semantic deficits may have been mildly impaired at repeating both single multisyllabic nonwords and lists of monosyllabic nonwords. It remains possible, therefore, that the cortical atrophy underlying SD impinges on the phonological system to some extent. Alternatively, the patients' nonword recall difficulties could have resulted from a reduction in the usual lexical-semantic support for nonwords in verbal STM. The following experiments aimed to examine the extent to which the patients' semantic impairments impacted on their nonword recall.

\section{RECALL OF NONWORDS PHONOLOGICALLY SIMILAR TO SEMANTICALLY KNOWN AND DEGRADED WORDS}

Several studies have demonstrated better recall of words that individual SD patients still understand relatively well, compared with words that are more semantically degraded (Jefferies et al., in press; Knott et al., 1997, 2000; Patterson et al., 1994). We constructed nonwords that were phonologically similar to known and degraded words in order to investigate the impact of semantic knowledge on nonword recall. Nonwords derived from known words should be recalled more accurately than nonwords derived from degraded words if stable semantic knowledge of phonologically similar words makes a contribution to nonword recall. The semantic binding hypothesis of Patterson and colleagues (1994) allows for such a contribution, as the bidirectional connections between phonological and semantic nodes might produce a stabilising influence on phonological representations even for nonwords. It follows that the stabilising semanticphonological interaction will be graded by the degree of conceptual dissolution in the SD cases. In line with this prediction, one previous study found fewer phonological errors for nonwords derived from known words compared with nonwords derived from degraded words in a patient with herpes simplex encephalitis, although there was no difference between the two sets of nonwords in recall accuracy (Caza et al., 2002).

\section{Method}

Five SD patients and 10 controls matched for age and educational level participated in this experiment, allowing 2 controls to be tested on each patient's material. BS was not included due to 
limitations on testing time. Sets of semantically known and degraded words were selected for each patient using a combination of naming, definition, and synonym judgment tests. The patients were asked to name 100 pictures from the Snodgrass set, as well as 13 colours and 20 body parts, and to provide definitions for the same items. Items that were both named and defined correctly were classified as known, and items that were neither named nor defined correctly were classified as degraded. Definitions were considered to be correct when they contained enough specific information to allow the item to be identified from its description (gestures, e.g., pointing at an item, were also accepted). The patients were also tested on a multiple-choice synonym judgment test in which they were asked questions like "which word is closest in meaning to rogue: scoundrel, polka or gasket?" The distracters and the target word were closely matched for word frequency and imageability. The test was administered twice on two separate occasions. Known items were correct on both occasions, and degraded items were incorrect on both occasions.

The words selected as known and degraded were matched for syllable length and word frequency as closely as possible on an item-by-item basis using data from Celex (Baayen, Piepenbrock, \& Van Rijn, 1993) and Kucera and Francis (1967). While this methodology should ensure a semantic difference between words assigned to the known and degraded categories, semantic degradation is thought to be a continuous variable. Consequently, the known words may not have been entirely intact and the degraded words may not have been entirely forgotten. Appendix A gives mean word frequency, length, imageability ratings, and set size for each patient's known and degraded words.

We constructed nonwords from the known and degraded words in two different ways. First, we formed monosyllabic and multisyllabic nonwords by switching the onsets between the items in each set (or occasionally substituting them). For example, the words "kangaroo" and "strawberry" were used to produce the nonwords "strangaroo" and "kawberry." Second, we constructed nonwords by exchanging the initial syllables of multisyllabic words. For example, the words "pineapple" and "strawberry" were combined to form the nonword "pineberry," and the words "motorbike" and "screwdriver" were combined to form the nonword "moedriver." This second method could not be used with single-syllable words. Consequently it was not possible to test JT, as very few multisyllabic items were available for him. We were also unable to test $\mathrm{SJ}$ in this part of the experiment, due to limitations on testing time.

Lists of known and degraded words and nonwords were assembled by selecting monosyllabic items at random without replacement until all the items had been used, and then repeating this process with the two-syllable and three-syllable items. Lists that contained items of more than one length were combined in the analysis with the pure lists that they were most similar to. This process was repeated three times; therefore, most items were presented in three separate lists. As the size of the word sets varied between the patients, each patient was tested on a different number of lists (see Appendix A). The known and degraded lists were presented alternately and the lists were yoked so that a particular known item and the degraded item in the same position in the following list formed a frequency-matched pair. The words and nonwords were tested in separate blocks, with the nonwords presented first. The word and nonword items were also yoked so that the nonwords appeared in the same list positions as the words they were derived from. The patients were tested on lists containing three and four items. EK was also tested on lists of five words. The controls were additionally tested on five-item lists and lists of six words. The items were read aloud at a rate of one word per second for immediate serial recall.

\section{Results}

Recall accuracy. Table 9 shows the percentage of words and nonwords recalled correctly by the patients and controls, averaging across lists containing three and four items, on which every participant was tested. Every patient's recall of the degraded words fell below the control range. SJ, KI, and GT also showed some impairment of 
JEFFERIES ET AL.

Table 9. Percentage of known and degraded words and nonwords recalled by patients and controls

\begin{tabular}{lcccccc}
\hline & $S J$ & $E K$ & $K I$ & $J T$ & $G T$ & Control mean (range) \\
\hline N (words, nonwords-onsets) & 186 & 216 & 216 & 114 & 165 & \\
$\quad$ N (nonwords-syllables) & - & 144 & 144 & - & 114 & \\
$\quad$ Words & & & & & & \\
$\quad$ Known & $78.0^{*}$ & 87.5 & $85.6^{*}$ & 92.1 & $86.1^{*}$ & $94.7(88-98)$ \\
$\quad$ Degraded & $64.0^{*}$ & $73.1^{*}$ & $72.7^{*}$ & $82.5^{*}$ & $64.2^{*}$ & $94.1(85-100)$ \\
$\quad$ & & & & & & \\
$\quad \begin{array}{l}\text { Nonwords } \\
\quad \text { Knsts exchanged }\end{array}$ & 46.8 & 40.7 & 53.7 & 57.0 & 37.6 & $53.7(28-77)$ \\
$\quad$ Known & 40.9 & $32.4^{*}$ & 40.3 & 39.5 & $17.0^{*}$ & $51.6(35-68)$ \\
$\quad$ Degraded & & & & & & \\
$\quad$ Knllables exchanged & $\mathrm{NT}$ & 36.8 & 51.4 & $\mathrm{NT}$ & 33.3 & $35.3(22-56)$ \\
$\quad$ Degraded & $\mathrm{NT}$ & $19.4^{*}$ & 50.7 & $\mathrm{NT}$ & $23.7^{*}$ & $39.2(28-58)$ \\
\hline
\end{tabular}

*Denotes abnormal performance. Table combines data from three- and four-item lists. $\mathrm{N}=$ number of items.

known word recall, possibly because their knowledge of these words was not entirely intact. In contrast, EK and JT recalled the known words at a normal level. All five patients recalled the nonwords derived from known words at a relatively normal level, whether they were constructed by exchanging onsets or initial syllables. EK and GT's recall of both sets of degraded nonwords was below the normal range, however, and SJ, KI, and JT's recall of nonwords derived from degraded words was at the bottom of the normal range.

Figure 1a shows the number of known and degraded words recalled by the patients and controls collapsing across the full range of list lengths. The known words were recalled more accurately than the degraded words by SJ, $t(99)=2.45$, $p<.05$, EK, $t(155)=3.21, p<.01$, KI, $t(107)=$ $2.84, p<.01$, and GT, $t(76)=4.22, p<.0001$, but not by JT, $t(45)=1.64$, ns, when the data from every list length was combined. However, JT's recall was at ceiling for both the known and the degraded words on three-item lists and he showed a significant known-degraded difference when four-item lists were analysed separately, $t(19)=$ $2.41, p<.05$. None of the controls showed a significant known-degraded recall difference, either when the full range of list lengths were included in the analysis, $t(96-202)<1.61, n s$, or when the analysis was restricted to five- and six-item lists, $t(41-76)<1$.
Turning to the nonwords constructed by exchanging onsets (see Figure 1b), KI, JT, and GT showed better recall of the items derived from known words, compared with the items derived from degraded words: KI, $t(120)=2.64, p<.01$; JT, $t(63)=2.33, p<.05 ;$ GT, $t(86)=4.28$, $p<.0001$. This difference approached significance for EK, $t(120)=1.74, p=.08$, and did not reach significance for SJ, $t(106)=1.03$, ns. None of the control participants showed a recall difference between the known and degraded nonwords constructed by exchanging onsets; all $t(88-166)<$ 1.33, ns, except for one participant who showed a numerical advantage for the degraded over the known words that approached significance, $t(160)=1.76, p=.08$. The recall difference between the known and degraded items constructed by exchanging initial syllables was significant for EK, $t(80)=2.91, p<.01$, but did not reach significance for KI, $t(82)<1$, or GT, $t(64)=1.74, p=.09$; see Figure 1c. As before, the control participants recalled the known and degraded items at an equivalent level; all $t(83-112)<1.72$, ns, except for two participants who showed a numerical advantage for the degraded words that approached significance, $t(108)=1.79, p=.08$ and $t(111)=1.92, p=.06$. In summary, all five patients consistently showed a recall advantage for known words over degraded words, and some patients (EK, KI, JT, and GT) 

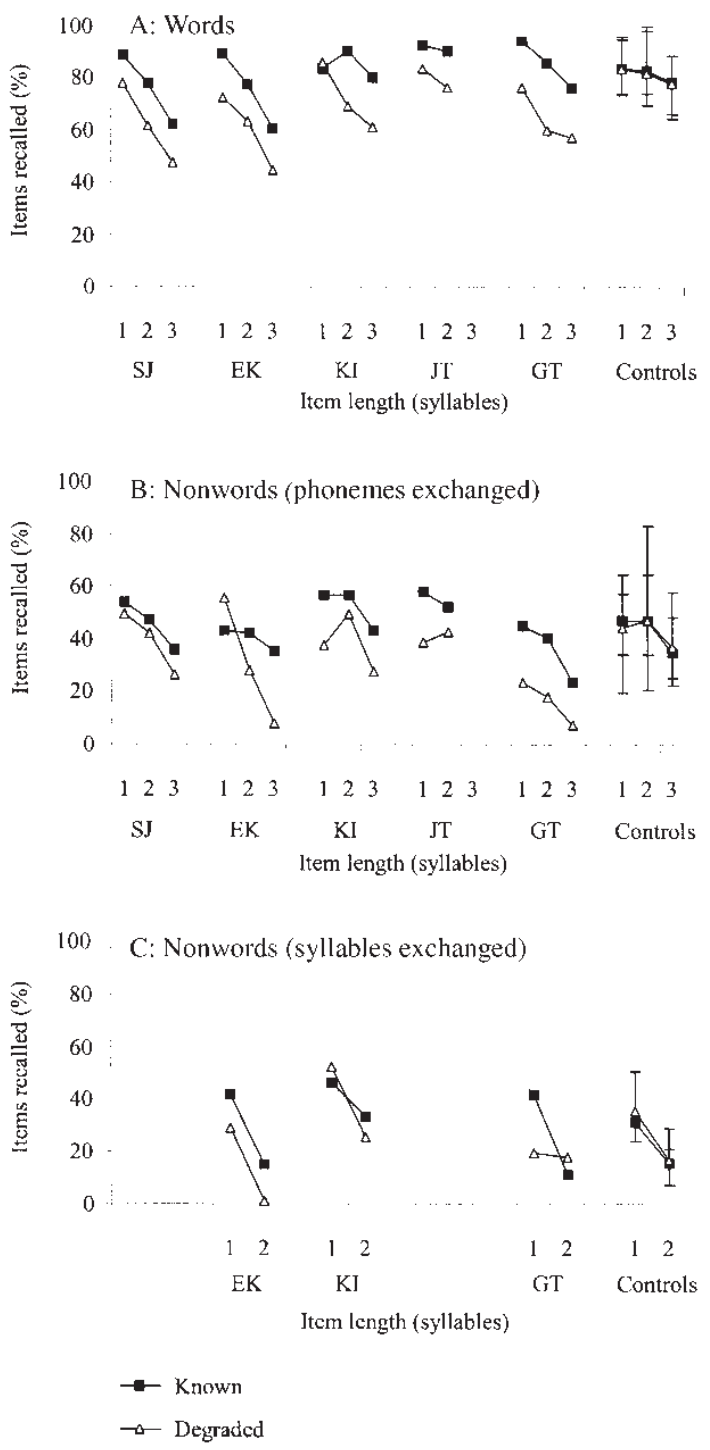

Figure 1. Recall of known and degraded words and nonwords of different syllable lengths.

also showed superior recall of nonwords derived from known words compared with nonwords derived from degraded words. KI and GT showed a known-degraded difference for nonwords constructed by exchanging onsets, but did not show such a difference for nonwords constructed by exchanging initial syllables. The nonwords constructed by exchanging syllables were less phonologically related to individual known and degraded words, possibly reducing the size of the known-degraded difference for these items. In contrast, EK did show better recall of nonwords constructed by exchanging syllables between known words, compared with nonwords constructed from degraded words in a similar way.

For EK, the size of the recall difference between nonwords derived from known and degraded words varied with the length of the items to be recalled (see Figure 1b). Although EK did not show an overall known-degraded difference for nonwords constructed by exchanging onsets (see above), she did show a significant difference on the longest three-syllable items, $t(23)=2.94$, $p<.01$. The known-degraded difference approached significance for two-syllable items, $t(52)=$ $1.90, p=.06$, but was not significant for onesyllable items, $t(37)=1.27$, ns. The other patients' recall of nonwords constructed from known and degraded words by exchanging onsets was less consistently affected by item length. KI, JT, and GT all showed a significant known-degraded difference for one-syllable nonwords: $\mathrm{KI}, t(39)=$ 2.07, $p<.05$; JT, $t(52)=2.43, p<.05 ; \mathrm{GT}$, $t(27)=2.32, p<.05$. GT also showed a significant known-degraded difference for two- and three-syllable items, $t(35)=3.20, p<.01$, and $t(18)=2.08, p=.05$, whereas KI and JT did not: KI two-syllable, $t(52)<1$; KI three-syllable, $t(19)=1.78, p=.09 ;$ JT two- and three-syllable: $t(8)<1$ (although few of these longer items were available for testing). SJ was the only patient who failed to show a significant known-degraded recall difference for nonwords constructed by exchanging onsets at every item length: one-syllable items, $t(34)<1$; two-syllable items, $t(46)<1$; threesyllable items, $t(21)=1.04, n s$.

Recall errors. Tables 10 to 12 show the types of errors that were made by the patients and controls in the recall of real words (Table 10), nonwords constructed by exchanging onsets (Table 11) and nonwords constructed by exchanging syllables (Table 12). These data combine the errors made on every list length, including the longer list 
JEFFERIES ET AL.

Table 10. Errors on known and degraded words

\begin{tabular}{lllllll}
\hline Error type & $S J$ & $E K$ & $K I$ & $J T$ & $G T$ & Control mean (range) \\
\hline Known words & & & & & & \\
Phonological & $.67^{*}$ & $.41^{*}$ & $.74^{*}$ & $.78^{*}$ & $.78^{*}$ & $.17(.05-.36)$ \\
Unrelated & $.17^{*}$ & $.08^{*}$ & .06 & $.11^{*}$ & .04 & $.02(0-.06)$ \\
Omission & .07 & .38 & .06 & .00 & .13 & $.49(.28-.76)$ \\
Other & .10 & .14 & .13 & .11 & .04 & $.31(.19-.44)$ \\
Degraded words & & & & & & $.93^{*}$ \\
Phonological & $.75^{*}$ & $.49^{*}$ & $.86^{*}$ & $.55^{*}$ & $.15(.03-.28)$ \\
Unrelated & $.10^{*}$ & $.12^{*}$ & .02 & $.30^{*}$ & .02 & $.02(0-.05)$ \\
Omission & .07 & .24 & .02 & .15 & .05 & $.50(.30-.80)$ \\
Other & .07 & .15 & .10 & .00 & .00 & $.33(.13-.51)$ \\
\hline
\end{tabular}

*Denotes abnormal performance. Table combines data across every list length tested. Figures show proportions of total errors.

Table 11. Errors on known and degraded nonwords constructed by exchanging onsets

\begin{tabular}{|c|c|c|c|c|c|c|}
\hline Error type & $S J$ & $E K$ & $K I$ & $J T$ & $G T$ & Control mean (range) \\
\hline \multicolumn{7}{|c|}{ Known nonwords } \\
\hline Phonological & .79 & .81 & .87 & .88 & .76 & $.67(.48-.88)$ \\
\hline Source & .06 & .03 & $.19^{*}$ & .08 & .07 & $.08(.01-.14)$ \\
\hline Unrelated & .18 & .13 & .10 & .06 & .21 & $.11(.05-.21)$ \\
\hline Omission & .03 & .05 & .02 & .06 & .03 & $.21(.01-.04)$ \\
\hline Other & .00 & .00 & .01 & .00 & .00 & $.01(0-.04)$ \\
\hline \multicolumn{7}{|c|}{ Degraded nonwords } \\
\hline Phonological & $.89^{*}$ & .77 & $.91^{*}$ & $.93^{*}$ & .80 & $.67(.43-.81)$ \\
\hline Source & .05 & .03 & .14 & .09 & .07 & $.09(.04-.14)$ \\
\hline Unrelated & .09 & $.18^{*}$ & .09 & .04 & $.15^{*}$ & $.10(.06-.14)$ \\
\hline Omission & .02 & .05 & .01 & .03 & .04 & $.21(.05-.44)$ \\
\hline Other & .00 & .00 & .00 & .00 & .00 & $.02(0-.04)$ \\
\hline
\end{tabular}

*Denotes abnormal performance. Table combines data across every list length tested. Figures show proportions of total errors.

Table 12. Errors on known and degraded nonwords constructed by exchanging initial syllables

\begin{tabular}{lllll}
\hline Error type & $E K$ & $K I$ & $G T$ & Control mean (range) \\
\hline Known nonwords & & & & \\
Phonological & $.76^{*}$ & $.80^{*}$ & $.83^{*}$ & $.59(.44-.68)$ \\
Source & $.11^{*}$ & .04 & $.11^{*}$ & $.06(.03-.09)$ \\
Unrelated & .15 & .17 & .14 & $.11(.07-.18)$ \\
Omission & .09 & .03 & .03 & $.29(.14-.46)$ \\
Other & .00 & .00 & .00 & $.01(0-.04)$ \\
Degraded nonwords & & & & $.57(.36-.67)$ \\
Phonological & $.76^{*}$ & $.89^{*}$ & $.83^{*}$ & $.06(.02-.08)$ \\
Source & .03 & .08 & $.10^{*}$ & $.10(.04-.19)$ \\
Unrelated & .13 & .07 & .15 & $.33(.08-.59)$ \\
Omission & .11 & .03 & .02 & $.01(0-.01)$ \\
Other & .00 & .01 & .00 &
\end{tabular}

*Denotes abnormal performance. Table combines data across every list length tested. Figures show proportions of total errors. 
lengths that the controls but not the patients were tested on, as the controls made very few word errors on the shorter list lengths. As in the previous experiment, errors were classified as phonological errors, omissions, other errors (order errors, intrusions, repetitions), and unrelated errors (if they could not be placed in the previous three categories). Some of the phonological errors, in which participants recalled nonwords as the words they had been derived from, were additionally classified as source errors.

Table 10 shows that the patients made an abnormally high proportion of phonological errors on both the known and degraded words. Phonological errors were the commonest type of word recall error for patients but were relatively uncommon among the controls. None of the patients showed a significant error difference between the known and degraded words, as phonological errors were relatively common for both, $\chi^{2}(3)$ from 1.34 to $5.12, n s$. In contrast, the patients' errors were more normal for the nonwords constructed by exchanging onsets between known words (see Table 11). Both the patients and controls made frequent phonological errors on these nonwords, and consequently the patients' phonological errors did not exceed the normal range. The number of phonological errors on the nonwords constructed from degraded words did exceed the normal range for three out of five patients, consistent with the notion that a reduction in semantic support led to a reduction in phonological coherence for these nonwords in STM. However, none of the patients made significantly different types of errors on the known and degraded nonword items, $\chi^{2}(3)$ between 1.39 and 4.33 , ns. For the nonwords constructed by moving syllables (see Table 12), the patients made a greater proportion of phonological errors compared with the controls, for both known and degraded items, and showed no significant differences between their errors on the known and degraded items, $\chi^{2}(3)$ between $<1$ and 4.18, ns. Source errors occurred relatively infrequently for both sets of nonwords and were largely equivalent for the patients and controls, although the patients occasionally exceeded the normal range.

\section{Discussion}

All five patients were found to recall relatively well-known words better than semantically degraded words, consistent with the view that semantics makes an important contribution to phonological coherence in STM. Furthermore, the ISR difference between known and degraded words remained substantial even for those patients who showed standard effects of phonological similarity and word length in ISR, intact nonword recall/repetition, and normal phonological processing skills, suggesting that this result is not dependent on additional phonological deficits. In addition, all but one of the patients recalled nonwords derived from relatively well-known words more accurately than nonwords derived from more semantically degraded words, suggesting that the semantic system may contribute to the phonological coherence of nonwords as well as words in STM. This effect appeared to be more marked for the patients with more severe semantic impairments. Unlike Caza et al. (2002), we did not find a substantial effect of semantic status on the frequency of different error types, although for three out of five patients, there was some suggestion that phonological errors occurred at an inflated rate for degraded nonwords and at a more normal level for known nonwords.

EK only showed a known-degraded difference in recall accuracy for longer multisyllabic nonwords. It seems likely that longer nonwords that are highly phonologically related to individual known words (and few other words) will produce some of the semantic activation associated with those real words, which will in turn feed back to the phonological system and support the coherence of longer nonwords in phonological STM. In contrast, shorter nonwords are likely to have several phonological neighbours that vary in their degree of semantic degradation, and consequently less clear differences may emerge. For example, if the word "fork" was semantically degraded, recall of the nonword "rork" might be supported by other phonologically similar words (e.g., "walk," "talk," etc.) that were still relatively well understood. Having said this, several other patients (KI, JT, 
and GT) did show significant known-degraded differences on the shorter nonwords, perhaps because their lexical-semantic deficits had markedly reduced the size of the nonwords' phonological neighbourhoods. These patients, who had particularly severe semantic impairments, may have essentially forgotten about a large number of words, making it less likely that nonwords derived from degraded words would be supported by other phonologically similar words.

Nonwords that were constructed by exchanging syllables between items may have produced more equivocal results than nonwords that were constructed by switching onsets for similar reasons. The nonwords that were constructed by exchanging onsets remained more phonologically similar to the individual words they were derived from than the nonwords constructed by exchanging syllables. The nonwords constructed by exchanging syllables may have shared their syllables with words that were both well understood and semantically degraded. Despite this, however, EK did show a significant known-degraded recall difference for these nonwords.

The results of this experiment suggest that semantic degradation can impact on the recall of nonwords. Therefore, it is not necessary to posit a separate phonological deficit to account for the impaired nonword recall observed in some SD patients. However, as SD patients are impaired at tasks like lexical decision, as well as at semantic tasks, it remains possible that a separate lexical impairment accounts for the poor nonword recall observed in SD, and this is likely to be the preferred interpretation of theorists who propose that separate lexical and semantic-level representations underpin language processing. In contrast, Patterson and colleagues assert that separate lexical-level representations are unwarranted (Patterson, Plaut, McClelland, Seidenberg, Behrmann, \& Hodges, 1996; Seidenberg \& McClelland, 1989), leading to the prediction that the patients' difficulties in ISR tasks and their markedly impaired comprehension result from the same central semantic impairment and not from dissociable impairments to independent conceptual and lexical representations. Our final experiment attempted to address this issue.

\section{DELAYED COPYING OF KNOWN AND DEGRADED ITEMS}

If the poor ISR of SD patients results from a central semantic deficit and not from a separable lexical impairment, then it should be possible to demonstrate superior performance for the known over the degraded items using an entirely nonverbal task. Previous work has suggested that delayed copying is highly sensitive to the breakdown of semantic memory in SD (Bozeat et al., 2003). SD patients typically omit distinctive features from their delayed copies, resulting in more prototypical drawings. They also show a tendency to include incorrect features that are shared across a domain; for example, adding four legs to a duck because most animals have four legs. Therefore, we examined delayed copying of pictures representing the known and degraded items used in the previous experiment, in order to determine whether a difference mirroring the known-degraded difference in ISR would emerge. If a single semantic deficit is viewed as underlying problems in both ISR and delayed copying, the same items should be impaired in the two tasks. If, in contrast, the ISR impairments of SD patients are underpinned by a lexical deficit that is independent of the semantic system, we would not expect to see a correlation between the items impaired in ISR and delayed copying, even if both semantic and lexical representations are compromised in SD.

\section{Method}

SJ, EK, KI, and JT participated in this experiment. We examined delayed copying of pictures from the Snodgrass set that corresponded to the known and degraded items used in the previous experiment. It was not possible to test all of the known and degraded items, as some were not imageable or were not included in the Snodgrass set. Items were only included if a Snodgrass picture was available for both the known and degraded items in a 
matched pair. We were able to test 20/32 item pairs for SJ, 15/36 for EK, 13/36 for KI, and 11/20 for JT. The patients were allowed to study each picture for as long as they wished before it was hidden from view. The delay between viewing the picture and attempting to copy it was filled with a distracter task designed to disrupt visual-spatial working memory. This task involved making an immediate copy of a geometric figure, similar to a simplified Rey figure, which was composed of a large rectangle, a square, and two circles. On each trial, these shapes were arranged in a different configuration. The patients began making their delayed copies of the Snodgrass pictures as soon as the distracter task was completed. SJ, KI, and JT copied a single distracter figure on each trial and EK copied two distracter figures, as pilot testing suggested her delayed copying showed little disruption with a single figure. The patients typically made no errors in their immediate copies of the distracter figures, in line with their intact performance on the Rey figure copy task (see Table 1). The known and degraded items in each pair were tested alternately.

\section{Results}

SJ, EK, and JT produced a response on every trial, whether the picture being copied was from the known or the degraded set. KI, in contrast, produced a response on every known trial but failed to respond on 7/13 degraded trials. On these trials, he indicated that he had entirely forgotten the picture to be copied, including its overall shape.

The quality of each patient's known and degraded drawings was evaluated using a feature listing technique (Bozeat et al., 2003). For each target picture, a list of features was complied into a checklist. The presence or absence of particular features (e.g., body, head, limbs, and tail) was recorded separately from modifiers of those features (e.g., body shape and size, long or short tail). The checklist was then used to identify features that had been correctly reproduced, omitted, or incorrectly included by the patients. The proportion of hits, misses, and intrusions for each patient's known and degraded items are shown in
Table 13, along with the total number of features identified. For all four patients, the proportion of hits to errors (misses and intrusions) was significantly higher for known items compared with degraded items: SJ, $\chi^{2}(3)=18.54, p<.0001$; $\mathrm{EK}, \chi^{2}(3)=9.29, p<.01 ; \mathrm{KI}, \chi^{2}(3)=32.22$, $p<.0001 ; \mathrm{JT}, \chi^{2}(3)=7.19, p<.01$.

\section{Discussion}

This experiment demonstrated that the ISR advantage for known over degraded items extended to a nonverbal delayed copying task. The same items were relatively well preserved and impaired in both ISR and delayed copying, suggesting that a central semantic deficit, which impinged on both the verbal and nonverbal domains, underpinned the patients' ISR impairments. Although it is conceivable that the atrophy underlying SD could encroach on independent semantic and lexical representations in such a way that lexical and semantic deficits would correlate across patients, this two-deficit account could not easily accommodate the finding that the same items are impaired in verbal and nonverbal tasks. This finding also suggests that the ISR difference between nonwords derived from known and degraded words resulted from the patients' semantic impairments, rather than from an independent lexical deficit, and therefore points to a genuine semantic contribution to nonword recall.

Table 13. Delayed copying of known and degraded items

\begin{tabular}{lcccc}
\hline Error type & $S J$ & $E K$ & $K I$ & $J T$ \\
\hline Known items & & & & \\
Hits & .84 & .72 & .47 & .66 \\
Misses & .13 & .25 & .43 & .28 \\
Intrusions & .03 & .03 & .10 & .08 \\
Total features & 256 & 193 & 142 & 150 \\
Degraded items & & & & \\
Hits & .69 & .58 & .19 & .50 \\
Misses & .24 & .34 & .76 & .39 \\
Intrusions & .07 & .08 & .06 & .11 \\
Total features & 335 & 220 & 220 & 135 \\
\hline
\end{tabular}

Table shows hits, misses, and intrusions as a proportion of the total number of hits plus errors. 


\section{GENERAL DISCUSSION}

This study examined the performance of six patients with semantic dementia (SD) on a range of phonological processing and verbal STM tasks (summarised in Table 14), in order to explore the suggestion that semantics makes a major and necessary contribution to the coherence of items in verbal STM. According to this viewpoint, pure semantic impairments will result in phonological breakdown in immediate serial recall (ISR) tasks because of the normal interactive nature of the phonological and semantic systems, and it is not necessary to posit additional phonological or lexical impairments to account for the poor verbal STM performance of SD patients (Patterson et al., 1994). Alternatively, it has been argued that SD patients who show poor ISR performance have additional lexical-phonological deficits (McCarthy \& Warrington, 2001).

In a range of tasks requiring phonological segmentation, discrimination between minimally different pairs of items, and rhyme judgement and production, the patients with the least impaired semantics performed normally, whereas the patients with more severe semantic deficits showed some mild weaknesses. Although this pattern is consistent with the view that the atrophy underlying SD ultimately impacts on phonological as well as semantic representations, an alternative possibility is that the patients' semantic impairments made it difficult for them to perform these tasks successfully. Given that they required the maintenance and manipulation of phonological representations, it seems likely that these tasks would not have been immune from the impact of semantic degradation if semantics does play a major role in constraining phonological activation. This may have been particularly true of the rhyme judgement task; more widespread deficits may have been observed on this task (see Table 14) because it required the phonology of two words to be maintained accurately while they were compared.

We also examined the effect of phonological similarity and word length on the patients' ISR performance and found influences that were within the normal range for all but the most severely impaired patients. These findings suggest that the patients with milder semantic impairments, in common with normal participants, relied heavily on a phonological code in ISR. Although the size of the phonological similarity effect may have been reduced in the more severely impaired patients, several recent studies have found that phonological similarity interacts with lexicality in ISR (Gathercole et al., 2001; Lian, Karlsen, \& Winsvold, 2001) and, consequently, semantic impairments might be expected to produce a reduction in the size of the phonological similarity effect in the absence of additional phonological deficits. In normal participants, phonological similarity effects are larger for words than for nonwords, suggesting that the phonological similarity effect may have its roots in the lexical-semantic binding process that operates for words and to a lesser extent for word-like nonwords. As this process is apparently disrupted in SD patients, the phonological similarity effect may be reduced in size.

Turning to the issue of ISR for nonwords, the majority of the SD patients showed normal recall of both single multisyllabic nonwords and strings of monosyllabic nonwords. Moreover, all the patients showed a reduction of the normal lexicality effect, suggesting that their semantic deficits had a larger impact on word than nonword recall. Again, there was some suggestion of a mild weakness in the patients with the most severe semantic impairments, which would be consistent with the disease process affecting phonological as well as semantic representations. Importantly, however, we also found better recall for nonwords that were phonologically similar to relatively well known compared with semantically degraded words, particularly for the more impaired cases. This ISR difference, which points to a semantic contribution to nonword recall, could account for the nonword recall deficits of some SD patients.

These results are summarised in Table 14. The two mildest patients, SJ and BS, showed virtually normal performance in every task tapping phonological processing, whereas the other four cases showed some subtle difficulties in several of the tasks. These deficits were particularly marked in 
Table 14. Summary of results for each patient

\begin{tabular}{l}
\hline \\
\hline Phoneme segmentation
\end{tabular}

GT, who was the most severely semantically impaired case included in this study. The presence or absence of a known-degraded difference in nonword recall mirrored the pattern of results obtained on the phonological tasks. The patients who showed mild phonological deficits also invariably displayed a known-degraded difference in ISR for nonwords. In contrast, SJ and EK, who had comparatively mild semantic impairments, did not show consistently better recall of nonwords that were derived from relatively well-understood words. These results are consistent with the suggestion that the deficits displayed by the more severely impaired patients in phonological tasks resulted from their marked semantic impairments.

Our results cannot rule out the possibility that phonological as well as semantic representations are compromised in the later stages of SD, although we did not obtain any conclusive evidence of such a deficit. Although the patients' poor performance on phonological tests might have been indicative of a mild phonological problem, interactive theories appear to predict that severe semantic degradation should lead to some difficulties on these tasks, even in the absence of an additional phonological impairment. Our results strongly suggest, however, that the phonological coherence of semantically degraded items breaks down in SD patients even in the absence of additional phonological problems. All of the patients examined here showed a significant ISR advantage for known over degraded words, even those patients who showed no signs of additional phonological impairment. In contrast, as noted in the Introduction, several previous studies have failed to obtain significant recall differences between known and degraded words. It seems likely that the relatively large set sizes used in this investigation may have contributed to its positive outcome, as known-degraded recall differences can be reduced when small set sizes are used (Jefferies et al., in press).

We did not find a difference between known and degraded words in the incidence of phonological errors, in contrast with several studies (e.g., Knott et al., 1997; Patterson et al., 1994), principally because our patients made an abnormally large number of phonological errors on both the known and the degraded items. Although the semantic binding hypothesis clearly predicts a known-degraded difference in the incidence of phonological errors, previous research has shown that methodological factors, in particular the methods used to select words as known/degraded, 
can impact on the size of such differences (Jefferies et al., in press).

The ISR advantage for the known over the degraded items extended to a nonverbal delayed picture-copying task. The patients were able to reproduce more of the correct features when they made delayed copies of drawings that represented their known items, compared with their degraded items. As the same items were relatively well preserved in both ISR and delayed copying, it seems likely that a central semantic deficit, and not a separable lexical impairment, underpinned the patients' ISR impairments. A parallel argument was made in a recent study in which a very similar decline in performance was observed for lexical and object decision (Rogers, Lambon Ralph, Hodges, \& Patterson, 2004), and these findings follow previous studies that strongly point to a central semantic deficit at the heart of this disorder (Bozeat, Lambon Ralph, Patterson, Garrard, \& Hodges, 2000; Lambon Ralph \& Howard, 2000). This reasoning applies equally to ISR for words and nonwords; therefore, the patients' deficits in nonword recall apparently resulted from their marked semantic difficulties and not from any independent impairment of lexical representations. Consequently, our findings point to a genuine semantic contribution to nonword recall.

The suggestion of a semantic contribution to nonword recall is a novel finding that requires some further discussion. There are at least two mechanisms by which this effect could occur. First, interactive models (e.g., N. Martin \& Saffran, 1997; Patterson et al., 1994) appear to predict that nonwords closely resembling known words will be recalled more accurately than those resembling degraded words, as bidirectional connections between phonology and semantics should help to stabilise the nonword segments that overlap with known words. This semantic contribution to nonword recall is expected to be greatest for longer multisyllabic items, as long nonwords that are highly phonologically related to particular known words and few other words (e.g., "strangeroo"-a close neighbour of "kangaroo") should produce strong and coherent activation of specific semantic representations relating to those individual words.
EK did show a larger ISR difference between known and degraded nonwords for longer items and normal participants might also be expected to exhibit semantic effects for longer nonwords. In contrast, short nonwords are likely to have many phonological neighbours, all of which should produce activation in the semantic system. As a nonword like "rork" will have several phonological neighbours with disparate meanings, e.g., walk, hawk, fork (i.e., the mappings between semantics and phonology are not systematic), it is less clear how semantic activation could helpfully constrain the phonological trace of these items.

Several of the more severely semantically impaired patients did show significant knowndegraded differences on the shorter nonwords. The PDP framework (Patterson et al., 1994; Plaut \& Kello, 1999) might allow for an effect of semantic impairment even for short nonwords as, according to this approach, stable phonological representations are acquired in the presence of semantics. For example, in the "model-T" framework of Plaut and Kello, activation between acoustic, phonetic, and semantic representations is accomplished through a common set of hidden units. In effect, these units and their associated connections to the surface representations form a "phonological" space. Given that there are no direct connections between acoustic and phonetic units, repetition of words and nonwords is achieved by passing activation through these hidden units. The nature and accuracy of repetition will reflect the "topography" of the high-dimensional space formed during the learning phase in the model. Given the high degree of systematicity between acoustic and phonetic representations, the representational space will predominantly reflect these associations (i.e., will form something like phonological representations). In addition, however, the model is required to transform these intermediate representations into meaning, and thus semantic memory will also influence the formation of this "phonological" space to at least some degree.

This framework provides a concrete instantiation of the semantic binding hypothesis (Patterson et al., 1994) in that phonological representations automatically interact with meaning. For words, 
repetition is likely to be more accurate when the corresponding semantic representations are relatively intact (i.e., words that are known) than impaired (degraded words). In addition, once semantic impairment is sufficiently severe, the removal of semantic representations will have an impact, albeit subtle, on the generic "phonological" space formed across the connections to the hidden units. Given that this space is used for all items, both words and nonwords should be affected. The impaired ISR of our SD patients is, therefore, most consistent with the view that semantics does make a major and crucial contribution to phonological STM, even in the absence of independent damage to phonological and lexical representations.

\author{
Manuscript received 7 May 2003 \\ Revised manuscript received 31 October 2003 \\ Revised manuscript accepted 4 February 2004 \\ PrEview proof published online 22 November 2004
}

\section{REFERENCES}

Baayen, R. H., Piepenbrock, R., \& Van Rijn, H. (1993). The CELEX lexical database [CD-ROM]. Philadelphia, PA: Linguistic Data Consortium, University of Pennsylvania.

Baddeley, A. D. (1966). Short-term memory for word sequences as a function of acoustic, semantic and formal similarity. Quarterly Journal of Experimental Psychology, 18, 362-365.

Baddeley, A. D., Gathercole, S., \& Papagno, C. (1998). The phonological loop as a language learning device. Psychological Review, 105, 158-173.

Baddeley, A. D., Lewis, V., \& Vallar, G. (1984). Exploring the articulatory loop. Quarterly Journal of Experimental Psychology, 36, 233-252.

Baddeley, A. D., Thomson, N., \& Buchanan, M. (1975). Word length and the structure of short-term memory. Journal of Verbal Learning and Verbal Behavior, 14, 575-589.

Bailey, T. M., \& Hahn, U. (2001). Determinants of wordlikeness: Phonotactics or lexical neighborhoods? Journal of Memory and Language, 44, 568-591.

Bird, H., Franklin, S., \& Howard, D. (2001). Age of acquisition and imageability ratings for a large set of words, including verbs and function words. Behavior Research Methods, Instruments and Computers, 33, 73-79.
Bird, H., Lambon Ralph, M. A., Seidenberg, M., McClelland, J. L., \& Patterson, K. (2003). Deficits in phonology and past-tense morphology: What's the connection? Journal of Memory and Language, 48, 502-526.

Bourassa, D. C., \& Besner, D. (1994). Beyond the articulatory loop: A semantic contribution to serial order recall of subspan lists. Psychonomic Bulletin and Review, 1, 122-125.

Bozeat, S., Lambon Ralph, M. A., Graham, K., Patterson, K., Wilkin, H., Rowland, J., Rogers, T. T., \& Hodges, J. R. (2003). A duck with four legs: Investigating the structure of conceptual knowledge using picture drawing in semantic dementia. Cognitive Neuropsychology, 20, 27-47.

Bozeat, S., Lambon Ralph, M. A., Patterson, K., Garrard, P., \& Hodges, J. R. (2000). Non-verbal semantic impairment in semantic dementia. Neuropsychologia, 38, 1207-1215.

Bozeat, S., Lambon Ralph, M. A., Patterson, K., \& Hodges, J. R. (2002). The influence of personal familiarity and context on object use in semantic dementia. Neurocase, 8, 127-134.

Caza, N., Belleville, S., \& Gilbert, B. (2002). How loss of meaning with preservation of phonological word form affects immediate serial recall performance: A linguistic account. Neurocase, 8, 255-273.

Coltheart, M. (1981). The MRC Psycholinguistic Database. Quarterly Journal of Experimental Psychology, 33A, 497-505.

Conrad, R. (1964). Acoustic confusion in immediate memory. British Journal of Psychology, 55, 75-84.

Conrad, R., \& Hull, A. J. (1964). Information, acoustic confusion and memory span. British Journal of Psychology, 55, 439-432.

Cowan, N., Day, L., Saults, J. S., Kellar, T. A., Johnson, T., \& Flores, L. (1992). The role of verbal output time in the effects of word-length on immediate memory. Journal of Memory and Language, 31, 1-17.

Dell, G. S., \& O'Seaghda, P. G. (1992). Stages of lexical access in language production. Cognition, 42, 287314.

Folstein, M. F., Folstein, S. E., \& McHugh, P. R. (1975). Mini-mental state: A practical method for grading the cognitive state of patients for the clinician. Journal of Psychiatric Research, 12, 189-198.

Forde, E. M. E., \& Humphreys, G. W. (2002). The role of semantic knowledge in short-term memory. Neurocase, 8, 13-27.

Funnell, E. (1995). Objects and properties: A study of the breakdown of semantic memory. Memory, 3, 497-518. 
Funnell, E. (1996). Response biases in oral reading: An account of the co-occurrence of surface dyslexia and semantic dementia. Quarterly Journal of Experimental Psychology, 49A, 417-446.

Gathercole, S. E. (1995). Is nonword repetition a test of phonological memory or long-term knowledge? It all depends on the nonwords. Memory and Cognition, 23, 83-94.

Gathercole, S. E., Frankish, C. R., Pickering, S. J., \& Peaker, S. (1999). Phonotactic influences on shortterm memory. Journal of Experimental Psychology: Learning, Memory, and Cognition, 25, 562-562.

Gathercole, S. E., \& Martin, A. J. (1996). Interactive processes in phonological memory. In S. E. Gathercole (Ed.), Models of short-term memory. Hove, UK: Psychology Press.

Gathercole, S. E., Pickering, S. J., Hall, M., \& Peaker, S. M. (2001). Dissociable lexical and phonological influences on serial recognition and serial recall. Quarterly Journal of Experimental Psychology, 54A, $1-30$.

Gathercole, S. E., Willis, C. S., Baddeley, A. D., \& Emslie, H. (1994). The Children's Test of Nonword Repetition: A test of phonological working memory. Memory, 2, 103-127.

Gathercole, S. E., Willis, C., Emslie, H., \& Baddeley, A. D. (1991). The influence of number of syllables and wordlikeness on children's repetition of nonwords. Applied Psycholinguistics, 12, 349-367.

Hodges, J. R., \& Patterson, K. (1995). Is semantic memory consistently impaired early in the course of Alzheimer's disease? Neuroanatomical and diagnostic implications. Neuropsychologia, 33, 441-459.

Hodges, J. R., Patterson, K., Oxbury, S., \& Funnell, E. (1992). Semantic dementia: Progressive fluent aphasia with temporal lobe atrophy. Brain, 115, 1783-1806.

Howard, D., \& Patterson, K. (1992). Pyramids and Palm Trees: A test of semantic access from pictures and words. Bury St Edmunds, UK: Thames Valley Test Company.

Hulme, C., Maughan, S., \& Brown, G. D. A. (1991). Memory for familiar and unfamiliar words: Evidence for a long-term memory contribution to short-term memory span. Journal of Memory and Language, 30, 685-701.

Hulme, C., Roodenrys, S., Schweickert, R., Brown, G. D. A., Martin, S., \& Stuart, G. (1997). Wordfrequency effects on short-term memory tasks: Evidence for a redintegration process in immediate serial recall. Journal of Experimental Psychology: Learning, Memory, and Cognition, 23, 1217-1232.
Jefferies, E., Jones, R., Bateman, D., \& Lambon Ralph, M. A. (in press). When does word meaning affect immediate serial recall in semantic dementia? Cognitive, Affective and Behavioral Neuroscience.

Jefferies, E., Patterson, K., Jones, R. W., Bateman, D., \& Lambon Ralph, M. A. (2004). A category-specific advantage for numbers in verbal short-term memory: Evidence from semantic dementia. Neuropsychologia, 42, 639-660.

Kay, J., Lesser, R., \& Coltheart, M. (1992). Psycholinguistic Assessments of Language Processing in Aphasia. Hove, UK: Lawrence Erlbaum Associates Ltd.

Knott, R., Patterson, K., \& Hodges, J. R. (1997). Lexical and semantic binding effects in short-term memory: Evidence from semantic dementia. Cognitive Neuropsychology, 14, 1165-1216.

Knott, R., Patterson, K., \& Hodges, J. R. (2000). The role of speech production in auditory-verbal shortterm memory: Evidence from progressive fluent aphasia. Neuropsychologia, 38, 125-142.

Kucera, H., \& Francis, W. N. (1967). Computational analysis of present-day American English. Providence, RI: Brown University Press.

Lambon Ralph, M. A., \& Howard, D. (2000). Gogi aphasia or semantic dementia? Simulating and assessing poor verbal comprehension in a case of progressive fluent aphasia. Cognitive Neuropsychology, 17, 437-465.

Lambon Ralph, M. A., McClelland, J. L., Patterson, K., Galton, C. J., \& Hodges, J. R. (2001). No right to speak? The relationship between object naming and semantic impairment: Neuropsychological evidence and a computational model. Journal of Cognitive Neuroscience, 13, 341-356.

Lezak, M. (1976). Neuropsychological assessment. New York: Oxford University Press.

Lian, A., Karlsen, P. J., \& Winsvold, B. (2001). A reevaluation of the phonological similarity effect in adults' short-term memory of words and non-words. Memory, 9, 281-299.

Martin, N., \& Saffran, E. M. (1997). Language and auditory-verbal short-term memory impairments: Evidence for common underlying processes. Cognitive Neuropsychology, 14, 641-682.

Martin, R. C., \& Lesch, M. (1996). Associations and dissociations between language impairment and list recall: Implications for models of STM. In S. E. Gathercole (Ed.), Models of short-term memory (pp. 149-178). Hove, UK: Psychology Press.

Martin, R. C., Lesch, M. F., \& Bartha, M. C. (1999). Independence of input and output phonology in 
word processing and short-term memory. Journal of Memory and Language, 41, 3-29.

Martin, R. C., Shelton, J., \& Yaffee, L. S. (1994). Language processing and working memory: Neuropsychological evidence for separate phonological and semantic capacities. Journal of Memory and Language, 33, 83-111.

McCarthy, R. A., \&Warrington, E. K. (1987). The double dissociation of short-term memory for lists and sentences: Evidence from aphasia. Brain, 110, 1545-1563.

McCarthy, R. A., \& Warrington, E. K. (2001). Repeating without semantics: Surface dysphasia? Neurocase, 7, 77-87.

Patterson, K., Graham, N., \& Hodges, J. R. (1994). The impact of semantic memory loss on phonological representations. Journal of Cognitive Neuroscience, 6, 57-69.

Patterson, K., \& Hodges, J. R. (2000). Semantic dementia: One window on the structure and organisation of semantic memory. In F. Boller \& J. Grafman (Eds.), Handbook of neuropsychology, Vol. 2: Memory and its disorders (2nd ed., pp. 313-333). Amsterdam: Elsevier.

Patterson, K., \& Marcel, A. J. (1992). Phonological ALEXIA or PHONOLOGICAL alexia? In J. Alegria, D. Holender, J. Junca de Morais, \& M. Radeau (Eds.), Analytic approaches to buman cognition (pp. 259-274). Amsterdam: Elsevier.

Patterson, K., Plaut, D. C., McClelland, J. L., Seidenberg, M. S., Behrmann, M., \& Hodges, J. R. (1996). Connections and disconnections: A connectionist account of surface dyslexia. In J. A. Reggia, E. Ruppin, \& R. S. Berndt (Eds.), Neural modelling of brain and cognitive disorders (pp. 177-199). Singapore: World Scientific.

Plaut, D. C., \& Kello, C. T. (1999). The emergence of phonology from the interplay of speech comprehension and production: A distributed connectionist approach. In B. MacWhinney (Ed.), The emergence of language. Mahwah, NJ: Lawrence Erlbaum Associates Inc.

Poirier, M., \& Saint-Aubin, J. (1995). Memory for related and unrelated words: Further evidence on the influence of semantic factors in immediate serial recall. Quarterly Journal of Experimental Psychology, 48A, 384-404.

Raven, J. C. (1962). Coloured progressive matrices sets $A$, $A B, B$. London: $\mathrm{H}$. K. Lewis.

Rogers, T. T., Lambon Ralph, M. A., Hodges, J. R., \& Patterson, K. (2004). Natural selection: The impact of semantic impairment on lexical and object decision. Cognitive Neuropsychology, 21, 331-352.
Roodenrys, S., \& Hinton, M. (2002). Sublexical or lexical effects on serial recall of nonwords? Journal of Experimental Psychology: Learning, Memory, and Cognition, 28, 29-33.

Schweickert, R. (1993). A multinomial processing tree model for degradation and redintegration in immediate recall. Memory and Cognition, 21, 168-175.

Seidenberg, M., \& McClelland, J. (1989). A distributed developmental model of word recognition and naming. Psychological Review, 96, 523-568.

Service, E. (1998). The effect of word length on immediate serial recall depends on phonological complexity, not articulatory duration. Quarterly Journal of Experimental Psychology, 51A, 283-304.

Snowden, J. S., Goulding, P. J., \& Neary, D. (1989). Semantic dementia: A form of circumscribed cerebral atrophy. Behavioural Neurology, 2, 167-182.

Snowden, J. S., Griffiths, H., \& Neary, D. (1994). Semantic dementia: Autobiographical contribution to preservation of meaning. Cognitive Neuropsychology, 11, 265-288.

Snowden, J. S., Neary, D., \& Mann, D. M. A. (Eds.). (1996). Frontotemporal lobar degeneration: Frontotemporal dementia, progressive aphasia, semantic dementia. London: Churchill Livingstone.

Treiman, R., \& Danis, C. (1988). Short-term memory errors for spoken syllables are affected by the linguistic structure of the syllables. Journal of Experimental Psychology: Learning, Memory, and Cognition, 14, 145-152.

Vallar, G., \& Papagno, C. (2002). Neuropsychological impairments of verbal short-term memory. In A. D. Baddeley, M. Kopelman, \& B. A. Wilson (Eds.), The handbook of memory disorders. Oxford: John Wiley.

Walker, I., \& Hulme, C. (1999). Concrete words are easier to recall than abstract words: Evidence for a semantic contribution to short-term serial recall. Journal of Experimental Psychology: Learning, Memory, and Cognition, 25, 1256-1271.

Warrington, E. K. (1975). The selective impairment of semantic memory. Quarterly Journal of Experimental Psychology, 27, 635-657.

Warrington, E. K., \& James, M. (1991). The Visual Object and Space Perception battery. Bury St Edmunds, UK: Thames Valley Test Company.

Wechsler, D. (1987). Wechsler Memory Scale-Revised $(W M S-R)$. New York: Psychological Corporation.

Wechsler, D. (1997). Wechsler Memory Scale-Third Edition (WMS-III). London: The Psychological Corporation. 
JEFFERIES ET AL.

\section{APPENDIX A}

\section{The characteristics of the known and degraded items}

\begin{tabular}{|c|c|c|c|c|c|c|c|c|c|c|}
\hline & \multirow[b]{2}{*}{$\begin{array}{c}\text { Frequency } \\
\text { (Celex) }\end{array}$} & \multirow{2}{*}{$\begin{array}{c}\text { Frequency } \\
\text { (Kucera Eे } \\
\text { Francis, } \\
\text { 1967) }\end{array}$} & \multirow[b]{2}{*}{ Imageability } & \multicolumn{3}{|c|}{ Set size (words) ${ }^{\mathrm{a}}$} & \multicolumn{4}{|c|}{$N$ of items in list } \\
\hline & & & & $\begin{array}{l}\text { Mono- } \\
\text { syllabic }\end{array}$ & $\begin{array}{c}\text { Two } \\
\text { syllables }\end{array}$ & $\begin{array}{l}\text { Threet } \\
\text { syllables }\end{array}$ & 3 & 4 & 5 & 6 \\
\hline \multicolumn{11}{|l|}{ SJ } \\
\hline Known & 27.3 & $27.0^{*}$ & $540^{*}$ & 12 & 14 & 6 & 90 & 96 & 90 & 96 \\
\hline Degraded & 28.1 & $20.0^{*}$ & $514^{*}$ & & & & & & & \\
\hline \multicolumn{11}{|l|}{$E K$} \\
\hline Known & 43.7 & $31.9^{*}$ & $593^{*}$ & 13 & 15 & 8 & $108(72)$ & $108(72)$ & $105(75)$ & 108 \\
\hline Degraded & 42.9 & $38.6^{*}$ & $510^{*}$ & & & & & & & \\
\hline \multicolumn{11}{|l|}{$K I$} \\
\hline Known & 23.8 & $19.4^{*}$ & $596^{*}$ & 13 & 15 & 8 & $108(72)$ & $108(72)$ & $105(75)$ & 108 \\
\hline Degraded & 21.3 & $17.0^{*}$ & $597^{*}$ & & & & & & & \\
\hline \multicolumn{11}{|l|}{$J T^{\circ}$} \\
\hline Known & 71.3 & $45.4^{*}$ & $595^{*}$ & 16 & 2 & 2 & 54 & 60 & 60 & 60 \\
\hline Degraded & 67.3 & 43.1 & $596^{*}$ & & & & & & & \\
\hline \multicolumn{11}{|l|}{$G T$} \\
\hline Known & 54.3 & $42.9^{*}$ & $556^{*}$ & 10 & 12 & 6 & $81(54)$ & $84(60)$ & $85(55)$ & 84 \\
\hline Degraded & 54.0 & $38.4^{*}$ & $534^{*}$ & & & & & & & \\
\hline
\end{tabular}

${ }^{a}$ Number of items in each set of known or degraded words.

*Denotes that values were unavailable for some items.

Figures in parentheses denote number of multisyllabic nonwords constructed by exchanging syllables between items. 